\title{
Use of the Ready-to- Use Therapeutic Foods (RUTFs), for the Management of Malnutrition in People Living with HIV/AIDS in Omdurman Hospitall (VCT Centre)
}

\section{Dr. Suzan Ail Yousif Abo, ${ }^{2}$ Osama AwadSalih, ${ }^{3}$ Co.Mohamed Osman Hamed}

\author{
${ }^{1}$ Department of Human Nutrition, Faculty of Science and Art - Al Baha University, Al Bahah, \\ , Sudan. \\ 2Department of family science Ahfad University for Women Nutrition Center for Training \& Research \\ (NCTR), Khartoum, Sudan. \\ ${ }^{3}$ Department of Human and Nutrition, Sudan.
}

\section{ABSTRACT}

This study is an observational "before and after" randomized controlled trial study, using routinely collected data. The main objective is to evaluate the outcomes of patients with acquired immunodeficiency syndrome (AIDS) provided with Ready-to-use therapeutic food (RUTF) and nutritional counseling. A total of 7 HIV patients were selected from those who attending Omdurman VCT Center at Omdurman Teaching Hospital during the period from September 2008 to March 2009.. Primary data was collected directly from HIV patients who attended Omdurman VCT Center at Omdurman Teaching Hospital using a questionnaire in addition to a checklist to record weight changes during intake of food regimen (RUTF). The Statistical Package for Social Science (SPSS) version 12.0 was used for data analysis.

Results showed that $71.4 \%$ of the respondents in the age group $31-40$ years, $71.4 \%$ were males and $28.6 \%$ were females. Most of the respondents (57.1\%) were married, having marginal occupations. The majority of the respondents (71.4\%) used pre ARV drugs as major medication, of them, $42.9 \%$ used it for a period from 6 months to one year. The majority of the respondents (85.7\%) did not complain about any type of food and drug interactions. The average Body Mass Index of the respondents (BMI) showed a relatively normal range $(18$ - 25). Use of RUTF showed improvement effect on patients, where T-test showed that there are significant differences in median weights between patients and the control group $(\mathrm{P} \leq 0.05)$.

The study highly recommends conduction of detailed studies on the importance of RUTF and other nutritional aspects for HIV/AIDS.

\section{Introduction}

HIV/AIDS is most prevalent in sub-Saharan Africa including Sudan, where it combines with other common conditions such as malnutrition and opportunistic infections to wreak devastation among families, communities, and nations. Malnutrition is common in patients with HIV resulting from anorexia, diarrhea, nausea, and vomiting associated with the disease process or the effects of treatment for HIVrelated illnesses, and the causes are multifactor (Anabwanivario, 2005; Timbo, and Tollefson, 1994; Ott, et al., 1994; Sharkey, 1992).

Adequate nutrition, which is achieved through consumption of a balanced healthy diet, consisting of locally available foods, fortified food and/or micronutrient supplements when appropriate, is vital for the health and survival of all individuals regardless of HIV status. Severe malnutrition has been associated with acquired immunodeficiency among children worldwide, and it is referred to as Nutritionally Acquired Immunodeficiency Syndrome or NAIDS (Guenter, et al., 1993). When these conditions are concurrent, their effect on the immune system is synergistic and the interaction between HIV infection and malnutrition leads to Nutritional and micronutrient deficiencies; growth failure and stunting in children. According to WHO, nutritional support is an integral part of a comprehensive response to HIV/AIDS, helping to maintain the immune system and sustain healthy levels of physical activity. There are 
well established scientific links among poor nutrition, food insecurity, and HIV/AIDS. However, the evidence base for identifying effective programming approaches is still evolving.

Determination of the appropriate timing is critical to the recovery of nutritional status in all patients, especially HIV-infected patients (Anabwanivario, 2005). Timely nutrition intervention is of utmost importance to patients with HIV and acquired immunodeficiency syndrome (AIDS). Hesitation can cause exacerbation of nutritional deficiencies that may lead to worsening malnutrition and eventual death.

\subsection{Justification}

It has been found that wasting is an indication of progression to acquired immune deficiency syndrome (AIDS), generally occurring as part of the wasting syndrome and closely correlated with the stage of the disease. By contrast, analysis of anthropometric data from a high prevalence HIV population showed that there was no association between disease stage and nutritional status, suggesting that malnutrition due to food shortage might have played an important role in the occurrence of wasting (Dannhauser, et al., 1999). For the World Health Organization (WHO, 2005a), the comprehensive care for PLWHA must include nutritional support. WHO recommends that symptomatic HIV and AIDS patients to increase their daily energy intake by $50 \%$ from the requirements of normal active HIV negative adult of $2430 \mathrm{Kcal}$ for male and $2170 \mathrm{kcal}$ for female but to keep proteins and vitamins and minerals intakes at normal daily requirement. Thus, the current study intended to shed light on the role of Ready To Use Therapeutic Foods (RUTF) as supportive factors for treatment and means to reduce weight loss among HIV/AIDS patients.

\subsection{Objectives}

\subsubsection{General Objective}

The objective is to evaluate the outcomes of patients with acquired immunodeficiency syndrome (AIDS) provided with Ready-to-use therapeutic food (RUTF) and nutritional counseling.

\subsubsection{Specific Objectives:}

1. To observe an improvement of the general nutritional status of the HIV/AIDS patient as a result of the introduction of the RUTF,

2. To estimate the amount of RUTF needed to correct the malnutrition in the targeted group

3. To assess the effect of nutritional counseling on improving the situation of malnutrition among the targeted group,
4. To estimate the average length of stay of the patients in the program course in order to effect the desired changes.

\section{General Background}

Human immunodeficiency virus and Acquired immunodeficiency syndrome (HIV/AIDS) remain a great challenge to public health, human rights, development, and national security. HIV/AIDS devastating for the individual who may be infected and its impact on communities and society at large is enormous. This disease affects those population groups that already vulnerable: children, women, the poor and the deprived millions of others whose life situation are further degrading by the denial of basic human rights. In1981, a report was written by Scientist Michael Gottieb, and published by the center of the disease control and prevention, alerted Physicians to an unusual constellation of fungal infections and pneumonia in otherwise healthy young gay men. The condition was later named Acquired Immunodeficiency Syndrome.(Gerald, 2002).

Global situation of HIV/AIDS already 3.1 million people around the world have died of AIDS, 570.000 of them children, more than 40.3 million are now living with HIV virus that causes AIDS. The most recent UNAIDS/WHO estimates show that in 2005 more 4.3 million people where newly infected with HIV/AIDS in Africa. Sub Saharan Africa the most affected region, Sub Saharan is now home to 29.4 million people living with HIV/AIDS approximately $3-5$ million new infections occurred in 2005. Adult and children died due to AIDS estimated 4.2 million in Sub Saharan African (UNAIDS, 2005).

South Africa has the largest number of HIV/AIDS patients in the world followed by Nigeria. Sudan is the largest country of Africa, it represents $8 \%$ of the total African surface, Sudan has a border with nine African countries, Kenya, Uganda, Congo, the Central African Republic, Chad, Libya, Egypt, Eritrea, and Ethiopia. Its total population is 34.512 million, WHO (2004) estimates $42 \%$ are below, the years of 15 ages. Chronic conflict in Sudan has enormously and negatively affected the health and nutrition of the marginalized population. The first case of HIV in Sudan was diagnosed in 1986, since the first diagnosis, the prevalence of HIV/AIDS in Sudan is increasing rapidly (AwadElkarimet al., 2000). Currently, little information is available regarding the prevalence of HIV/AIDS in Sudan due to years of civil war and limited epidemiological data. Estimated is that $2.6 \%$ of the adult population is infected (500.000 individuals) (WHO, 2005a). 


\subsection{HIV/AIDS Global Situation}

According to new data in the 2009 AIDS epidemic update, new HIV infections have been reduced by $17 \%$ over the past eight years. Since 2001, when the United Nations Declaration of Commitment on HIV/AIDS was signed, the number of new infections in sub-Saharan Africa is approximately $15 \%$ lower, which is about 400 000 fewer infections in 2008. In East Asia, HIV incidence has declined by nearly $25 \%$ and in South and South East Asia by $10 \%$ in the same time period. In Eastern Europe, after a dramatic increase in new infections among injecting drug users, the epidemic has leveled off considerably. However, in some countries, there are signs that HIV incidence is rising again. The report, released today by the Joint United Nations Programme on HIV/AIDS (UNAIDS) and the World Health Organization (WHO), highlights that beyond the peak and natural course of the epidemic HIV prevention programs are making a difference (WHO/UNAIDS, 2009).

Data from the AIDS Epidemic Update also show that at 33.4 million, (31.1 million-35.8 million) there are more people living with HIV than ever before as people are living longer due to the beneficial effects of antiretroviral therapy and population growth. However, the number of AIDS-related deaths has declined by over $10 \%$ over the past five years as more people gained to access the life-saving treatment. UNAIDS and WHO estimate that since the availability of effective treatment in 1996, some 2.9 million lives have been saved. Antiretroviral therapy has also made a significant impact in preventing new infections in children as more HIV-positive mothers gain access to treatment preventing them from transmitting the virus to their children. Around 200000 new infections among children have been prevented since 2001. In Botswana, where treatment coverage is $80 \%$, AIDSrelated deaths have fallen by over $50 \%$ over the past five years and the number of children newly orphaned is also coming down as parents are living longer (WHO/UNAIDS, 2009).

\section{$2.3 \mathrm{HIV} /$ AIDS in Sudan}

The geographical location and its borders with nine countries, most of them are formed AIDS belt (high HIV/AIDS prevalence countries), the population movement as a result of the political instability inside the country and in some of the neighboring countries as well as natural disasters and economic situation, all are regarded as major contributors to the prevalence of HIV/AIDS in Sudan (SNAP, 2004).

\subsubsection{Epidemic level and trend and gender data}

Sudan is experiencing the early stages of a generalized epidemic, and the predominant mode of transmission is heterosexual. WHO estimates indicate that, at the end of 2003, 220000 women 15-49 years old and 21 000 children were living with HIV/AIDS. According to data from a sentinel survey conducted by the Sudanese National AIDS Control Programme in 2004, HIV prevalence was estimated to be $1.0 \%$ among pregnant women, $2.3 \%$ among people with tuberculosis and $1.9 \%$ among people with sexually transmitted infections. Estimates derived from the WHO/UNAIDS Meeting on HIV Estimations and Projections in 2003 indicate an average adult prevalence of HIV/AIDS of $2.3 \%$. According to national sources, at the end of September 2004, 11511 cases of HIV/AIDS had been reported to the Sudanese National AIDS Control Programme since the beginning of the epidemic. The overall HIV prevalence in southern Sudan is difficult to estimate, as the civil strife of the past 21 years has led to the collapse of infrastructure, creating pockets of relatively isolated areas along with widespread poverty and illiteracy. Limited epidemiological data show a low prevalence in southern Sudan, but after many years of war and its effects, this area is facing an environment that could result in an accelerated spread of HIV (WHO, 2005b).

\subsubsection{Major vulnerable and affected groups}

Vulnerable groups include internally displaced people, refugees, sex workers, tea sellers, street children, truck drivers, prison inmates, and police and armed forces personnel. Increased prevalence of HIV infection among these vulnerable groups is driven by unsafe sex related to long civil conflicts, displacement, and high mobility and poverty. According to national estimates, the prevalence of HIV infection among vulnerable groups is $1 \%$ among antenatal care attendees, $10 \%$ among tea sellers in the southern district of Juba, $2 \%$ among prisoners, $1 \%$ among truck drivers, $1 \%$ among street children, $4 \%$ among sex workers and $4 \%$ among refugees. These figures represent data from government-controlled states in 2003. The existing data from southern Sudan show varying HIV prevalence rates: $1 \%$ in the general population in Rumbek (2003), $0.3 \%$ in a group of people with tuberculosis in Upper Nile (2001), 7\% in the general population in Yambio (2000) and 3\% in the general population in Yei County on the border (2003) with 
Uganda. The southern states are hardest hit with HIV/AIDS because of the lack of health services and health awareness, in addition to their proximity to high-prevalence neighboring countries (WHO, 2005c).

The following table shows the current situation of HIV/AIDS in Sudan:

\begin{tabular}{||l|l||}
\hline Population, 2008 & $42,300,000$ \\
\hline People living with HIV/AIDS, 2007 & 320,000 \\
\hline Women (aged 15+) with HIV/AIDS, 2007 & 170,000 \\
\hline Children with HIV/AIDS, 2007 & 25,000 \\
\hline Adult HIV prevalence (\%), 2007 & 1.4 \\
\hline AIDS deaths, 2007 & 25,000 \\
\hline
\end{tabular}

\subsection{Nutrition and HIV/AIDS}

HIV infection affects nutrition through increases in resting energy expenditure, reductions in food intake, nutrient malabsorption, and loss, and complex metabolic alterations that culminate in weight loss and wasting common in AIDS. The effect of HIV on nutrition begins early in the course of the disease, even before an individual may be aware that he or she is infected with the virus. Asymptomatic HIV-positive individuals require $10 \%$ more energy, and symptomatic HIVpositive individuals require $20 \%$ - 30\% more energy than HIV-negative individuals of the same age, sex, and physical activity level (WHO, 2003a).

The impact of pre-existing malnutrition on HIV susceptibility and disease progression is difficult to study, and knowledge in this area is still limited. A systematic review of the literature is now underway by the World Health Organization (WHO) (WHO, 2003a). Early studies demonstrated that weight loss and wasting were associated with increased risk of opportunistic infections (Wheeler, et al., 1998) and shorter survival time in HIV-positive adults, independent of their immune status (Suttmann, et al., 1995). Other studies showed that clinical outcome was poorer and risk of death was higher in HIV-positive adults with compromised micronutrient intake or status (Baum, et al., 1995; Tag, et al., 1996; Baum and Shor, 1998).

Micronutrient deficiencies may contribute to disease progression. Deficiencies of vitamins and minerals, such as vitamins $\mathrm{A}, \mathrm{B}$-complex, $\mathrm{C}$, and $\mathrm{E}$ and selenium and zinc, which are needed by the immune system to fight infection, are common in people living with HIV (Beach, et al., 1992). Deficiencies of anti-oxidant vitamins and minerals contribute to oxidative stress, a condition that may accelerate immune cell death and increase the rate of HIV replication (Shabert, et al., 1999). Daily micronutrient (antioxidant) supplementation improved body weight and body cell mass; reduced HIV RNA levels28; improved $\mathrm{CD}_{4}$ cell counts; and reduced the incidence of opportunistic infections in small studies of adults with AIDS, including those on antiretroviral therapy (Muller, et al., 2000; Mocchegiani, 2000). Larger clinical trials demonstrated that daily micronutrient supplementation increased survival in adults with low $\mathrm{CD}_{4}$ cell counts; prevented adverse birth outcomes when given during pregnancy; and reduced mother-tochild HIV transmission in nutritionally vulnerable women with more advanced HIV disease (Jaimton, et al., 2003; Fawzi, et al., 2002; Rousseau, et al., 2000).

2.4.1 Nutrient needs for people living with HIV/AIDS

There is an urgent need for a renewed focus on and use of resources for nutrition as a fundamental part of the comprehensive package of care at the country level. Action and investment to improve the nutrition of PLWHA should be based on sound scientific evidence, local resources, and programmatic and clinical experience with the prevention, treatment, and management of the disease and related infections. Although there are gaps in scientific knowledge, much can and should be done to improve the health, nutrition, and quality of care for PLWHA and their families and communities. The HIV/AIDS epidemic is occurring in populations where malnutrition is already endemic. As an urgent priority, greater political, financial and technical support should be provided for improving dietary quality and increasing dietary intake to recommended levels. In addition, focused evidencebased nutrition interventions should be part of all national AIDS control and treatment programs. Nutrition counseling, care and support interventions for PLWHA will vary according to nutritional status 
and the extent of disease progression (recommendations for specific nutrient requirements are given below). HIV-related infections, such as tuberculosis and diarrhea, not only have nutritional status as a significant determinant of their incidence and severity, but they also have severe nutritional consequences that commonly precipitate appetite loss, weight loss, and wasting. Prompt diagnosis and treatment of these conditions, including use of antiretroviral treatment (ART) when indicated, can contribute to improved nutrition and health. Improved understanding of nutrition/drug interactions is needed to inform HIV/AIDS treatment programs (WHO, 2003b).

\subsubsection{Macronutrients}

\subsubsection{Energy}

Studies point to low energy intake combined with increased energy demands due to HIV infection and related infections as the major driving forces behind HIV-related weight loss and wasting. Based on increased resting energy expenditure (REE) observed in studies of HIV-infected adults, it is recommended that energy be increased by $10 \%$ over accepted levels for otherwise healthy people. The goal is to maintain body weight in asymptomatic HIV-infected adults. Although studies of energy expenditure have not shown an increase in total energy expenditure (TEE), this may have been the result of individuals compensating by reducing activity-related energy expenditure (AEE). Since maintaining physical activity is highly desirable for preserving the quality of life and maintaining muscle tissue, it is undesirable that energy intake should only match a reduced level of AEE. The estimated energy requirement, therefore, allows for normal AEE levels on top of an increased level of REE (Coors, 2001).

Increased energy intake of about $20 \%$ to $30 \%$ is recommended for adults during periods of symptomatic disease or opportunistic infection to maintain body weight. This takes into account the increase in REE with HIV-related infections. However, such intakes may not be achievable during periods of acute infection or illness, and it has not been proven that such high intake levels can be safely achieved during such periods. Moreover, it is recognized that physical activity may be reduced during HIV-related infections and the recommended increased intake is based on the energy needed to support weight recovery during and after HIV related illnesses. Intakes should, therefore, be increased to the extent possible during the recovery phase, aiming for the maximum achievable up to $30 \%$ above normal intake during the acute phase (Grinspoon and Mulligan, 2003).

\subsubsection{Protein}

There are insufficient data at present to support an increase in protein intake for PLWHA above normal requirements for health i.e. $12 \%$ to $15 \%$ of total energy intake. Participants were aware of the published nutritional guidance suggesting increased protein intake during HIV infection, but they concluded that these recommendations were not based on rigorously conducted studies (Macallan, 1995).

\subsubsection{Fat}

There is no evidence that total fat needs are increased beyond normal requirements as a consequence of HIV infection. However, special advice regarding fat intake might be required for individuals undergoing antiretroviral therapy or experiencing persistent diarrhea (Kosmiski, 2003).

\subsubsection{Micronutrients}

The role of micronutrients in immune function and infectious disease is well established. However, the specific role of individual and multiple micronutrients in the prevention, care, and treatment of HIV infection and related conditions merits further attention. Several studies on micronutrients and HIV are underway, and new findings should be available soon. Observational studies indicate that low blood levels and decreased dietary intakes of some micronutrients are associated with faster HIV disease progression and mortality, and increased risk of HIV transmission. However, these studies' methodological limitations preclude definitive conclusions about the relationship between micronutrient intake and blood levels, and HIV infection (Fawzi, 2003; Friis. 2001; Friis, 2003).

Some studies show that there is evidence that supplements of, for example, B-complex vitamins, and vitamins $C$ and $E$, can improve immune status, prevent childhood diarrhea and enhance pregnancy outcomes, including better maternal prenatal weight gain and a reduction of fetal death, preterm birth and low birth weight. The effect of these micronutrients on HIV disease progression and mortality is under study. Micronutrients that have produced positive health outcomes in HIV uninfected populations include zinc supplementation for reducing diarrhea and pneumonia morbidity in children. The safety and effectiveness of zinc supplements in HIV-infected adults and children are now being studied. HIV-infected adults and children should consume diets that ensure micronutrient intakes at RDA levels. However, this may not be sufficient to correct nutritional deficiencies in 
HIV-infected individuals. Results from several studies raise concerns that some micronutrient supplements, e.g. vitamin A, zinc and iron, can produce adverse outcomes in HIV infected populations. Safe upper limits for daily micronutrient intakes for PLWHA still need to be established (Villamor, 2002).

\subsubsection{Vitamin A}

According to published reports, daily antenatal and postnatal vitamin A supplementation for HIV-infected women in well-designed randomized controlled trials not only did not reduce mother-to-child HIV transmission; in some settings it actually increased the risk. Thus, daily vitamin A intake by HIV-infected women during pregnancy and lactation should not exceed the RDA (Humphrey, 1999).

In areas of endemic vitamin A deficiency, WHO recommends that a single high-dose of vitamin A (200 $000 \mathrm{IU})$ be given to women as soon as possible after delivery, but no later than six weeks after delivery. Research is underway to assess further the effect of single-dose, postpartum vitamin A supplementation among HIV-infected women (Kumwenda, 2002).

\subsubsection{Multiple micronutrient supplements}

Micronutrient deficiencies are common in resourcelimited settings where HIV infection is prevalent. Some studies show that different multiple micronutrient supplements may have produced a broad range of beneficial outcomes. During pregnancy, daily multivitamin supplementation with multiple RDA levels of B-complex vitamins, and vitamins $\mathrm{C}$ and $\mathrm{E}$, improved birth outcomes in infants born to HIVinfected women, and increased maternal weight gain during pregnancy, hemoglobin concentration, and $\mathrm{CD}_{4}$ cell count. Daily use of this multivitamin supplement during lactation reduced postnatal HIV transmission and mortality in infants born to nutritionally vulnerable women and to women with immune deficiency. The supplements also reduced the risk of diarrhea and improved infants' immune status. Another micronutrient supplement formulation, with single RDA nutrient levels, improved birth weights among infants born to HIV infected women. The impact of single RDA multivitamin supplements on HIV disease progression and transmission, which was not assessed, requires further study (Fawzi, 2002).

Adequate micronutrient intake is best achieved through an adequate diet. However, in settings where these intakes and status cannot be achieved, multiple micronutrient supplements may be needed in pregnancy and lactation. Pending additional information, micronutrient intakes at the RDA level are recommended for HIV-infected women during pregnancy and lactation. The optimal micronutrient supplement composition that will be safe, ensure nutritional adequacy, and potentially produce the greatest benefits in HIV-infected pregnant and lactating women in different settings has not yet been defined. Additional research is required to determine the safety of nutrient supplements such as zinc, iron and vitamin $\mathrm{A}$, and to determine whether different multiple micronutrient supplements are needed for HIV-infected women compared with uninfected women (Clark and Semba, 2001).

\subsection{Nutrition of HIV/AID patients and antiretroviral therapy}

Antiretroviral therapy improves nutritional status, but ARVs may also have side effects and metabolic complications. Highly active antiretroviral therapy (HAART) improves nutritional status, independent of its effects on viral suppression and immune status, 33 although wasting still develops in some patients (Wanke, et al., 2000). ARV side effects such as nausea and vomiting may affect adherence to therapy, particularly in the first months of treatment (Chen, et al., 2003). Additional metabolic complications such as derangements in glucose and lipid metabolism, bone metabolism, and lactic academia have been associated with the use of certain ARV drugs (Shevitz and Knox, 2001). Research on the metabolic consequences of ARV therapy and appropriate strategies for their management is a growing field in industrialized countries.

There is a number of metabolic complications associated with the use of certain types of ARV, including derangement in glucose and lipid metabolism, bone metabolism and lactic acidaemia documented in industrialized countries. The consultation emphasized the need for evidence to improve management of these metabolic abnormalities in patients receiving ARV. Particular consideration was given to gaps in knowledge relating to ARV use in populations where malnutrition is endemic (Aungst, 2002).

ARV is an essential component of care for PLWHA. Nutritional interventions should be an integral part of all HIV treatment programs. Improved attention to diet and nutrition may enhance ARV acceptability, adherence and effectiveness. Countries should prepare for ARV access through training on how to manage ARV's nutritional dimension. More research is needed on appropriate strategies for such counseling and management in resource-limited settings (Batterham, et al., 2002).

Management of ARV interactions with food and nutrition. This includes providing information and support to help ARV clients manage side effects such as 
nausea and vomiting and prevent drug-food interactions. Side effects and interactions can negatively affect medication adherence and efficacy Supporting.

ARV clients in appropriate dietary responses to manage these conditions helps ensure successful treatment. In addition to nutrition counseling, food rations may be provided in food-insecure areas, particularly in cases where lack of food is interfering with treatment adherence and among those experiencing weight loss that is not reversed after treatment is initiated (Polsky, and Steinhart, 2001).

Therapeutic feeding for moderately and severely malnourished HIV-positive children and adults. This includes hospital-based stabilization and home- or community-based care using therapeutic (nutrient dense) foods, per WHO or local nutrition rehabilitation protocols. The foods and protocols used to treat severe malnutrition in the general population may be used for HIV-positive patients, although some adaptations may be required for adults and those experiencing severe symptoms (Sorensen, 2002).

\subsubsection{Management of drug and food interactions in HIV/AIDS therapy}

Usually, a medication that is both traditional and modern is used in the treatment of infection However, drugs can interact with food and nutrients and negatively affect the nutrition status of PLWHA. The side effects can affect the patients' adherence to medication. Food can also interact with drugs and affect drug efficacy. Nutritional implications of drug therapies need proper addressing in order to prevent malnutrition thus affecting the patient nutrition statuses further. Side effects can limit and reduce nutrient absorption leading to poor adherence in the long run. Proper nutritional management of side effects can help to minimize and improve patients' adherence to treatment (MILDAMY, 2005).

\subsubsection{Modern medications}

ARVs are the modern medications used to treat HIV/AIDS although they are not a cure They drastically reduce the replication of the virus in the body and slow the disease progression, food and drug interactions include (MILDAMY, 2005):

\subsubsection{Food effects on drug efficiency}

- Drugs effect on nutrient absorption and metabolism

- Side effects of medication on food intake and absorption

- Medication and food can interact to cause unhealthy side effects
- All of the above can have negative impacts on the nutrition status of PLWHA.

\subsubsection{Food intake affects drug efficacy}

Food can enhance or inhibit absorption, metabolism, and distribution of the medication The interactions vary from one drug to another. For example:

- Food affects the absorption of aspirin. Aspirin is best taken a few hours before a meal.

- Rifampicin and isoniazid absorption is reduced by food intake. Both of these drugs are used for TB treatment.

- Zidovudine absorption is affected by high fat, high calorie, and high protein diet.

- Some of the drugs such as quinine, fluconazole, chloroquine, AZT, nevirapine, AZT/ are best taken with food3 TC

- Rifampin, it is recommendable to be taken on an empty stomach 1or 2 hours after a meal (MILDAMY, 2005).

\subsubsection{Drug affect nutrient absorption and metabolism}

Modem medications inhibiting o enhancing nutrient absorption and metabolism may have negative effects on nutrition status. Dietary management may require either increasing food intake or nutrient supplementation for the nutrient affected side-effects of drugs requiring a dietary response. Many of these side effects may be alleviated either by appropriate, diet responses or by diet and medical response. Some of the side effects may include taste changes, loss of appetite, vomiting, diarrhea, nausea, and constipation. Reduced food intake and poor nutrient absorption can all lead to malnutrition and faster progression to HIV/AIDS (MILDAMY, 2005).

\subsection{Ready To Use Therapeutic Food (RUTF)}

RUTF is a generic term including different types of foods, such as spreads or compressed products suitable for feeding severely malnourished children. Among RUTF, spread RUTF are prepared with a simple technology which has already been successfully transferred to developing in countries with minimal industrial infrastructure. Hence, this paper will only refer to spread RUTFs, although other technologies could possibly be transferred in countries with more advanced industrial capacities (Briend, 2002).

The spread RUTF is made of powdered ingredients embedded in a lipid-rich paste, resulting in an energy dense food that resists microbial contamination(Briend, 2002). This RUTF is a mixture of milk powder, vegetable oil, sugar, peanut butter, and powdered vitamins and minerals. As the name implies, RUTF does not need to be prepared in any way prior to 
consumption, making it practical for use where cooking fuel and facilities are limiting constraints. RUTF has a very low water activity, thus it is impossible for significant bacterial growth to occur in these foods (Breind, 1997). This allows locally produced RUTF to be safely stored at ambient tropical conditions for 3-4 months. RUTF has a very high energy density, about $23 \mathrm{~kJ} / \mathrm{gm}(5.5 \mathrm{kcal} / \mathrm{g})$. A severely malnourished child can consume just a few spoonfuls of RUTF 5-7 times a day, and achieve sufficient nutrient intake for complete recovery. While RUTF must be consumed with water, no other foods are necessary for the rehabilitation of the malnourished child.

While the spread form of RUTF may not be the only therapeutic food that does not require cooking, it is the only one considered in this article, because it is the only one which has been locally produced in the developing world using modest technologies. The term RUTF in this article refers specifically to the spread form of RUTF (Briend, 2002).

Home-based therapy with RUTF limits the length of inpatient stay to the first phase of treatment, and then the entire second phase of treatment is completed at home with RUTF. Children typically stay in the hospital for one week with this approach compared with 2-3 wk for standard therapy. In 2001, home-based therapy with RUTF was shown to be efficacious in achieving complete recovery from childhood malnutrition in $95 \%$ of HIV-negative malnourished children at the primary teaching hospital in Malawi (Manary, et al., 2004). RUTF is an energy-dense paste that resists bacterial contamination because of its low water activity and does not need to be cooked before consumption (Briend, 2001). RUTF has been available as a commercial product packed in oxygen-free foil sachets (Nutriset, Malaunay, France). In 2002, locally produced RUTF was shown to be as effective as imported RUTF in Malawi and is less expensive and thus more widely available than is imported RUTF (Sandige, et al., 2004).

\subsubsection{RUTF as a Nutritional Support to People} Living with HIV/AIDS

Nutritional status is a major determinant of whether people survive HIV/AIDS, and it is now generally accepted that the comprehensive care of HIV/AIDSinfected people must include nutritional support (Bachou, et al., 2006). To be most effective, this support should be given before anti-retroviral therapy is started and as an adjunct to it. Ready-to-use foods have the potential to greatly improve the effectiveness of nutritional support to PLWHA. These foods are energy dense and therefore not bulky can be made with the appropriate balance of nutrients and do not require cooking. This means that the vitamins and minerals consumed can be carefully determined in advance and there are no additional labor demands placed on families. There is now increasing evidence that the provision of ready-to-use food can achieve positive impact in HIV-infected adults and children.

\subsubsection{Plumpy' nut}

The Plumpy'nut product is a high protein and high energy peanut-based paste in a foil wrapper. It tastes slightly sweeter than peanut butter. It is categorized by the WHO as a Ready-to-Use Therapeutic Food (RUTF). Plumpy'nut requires no water preparation or refrigeration and has a 2-year shelf life making it easy to deploy in difficult conditions to treat severe acute malnutrition. It is distributed under medical supervision, predominantly to parents of malnourished children where the nutritional status of the children has been assessed by a doctor or a nutritionist. The product was inspired by the popular Nutella spread. It is manufactured by Nutriset, a French company based in Normandy Rouen for use by humanitarian organizations for food aid distribution. The ingredients are peanut paste, vegetable oil, powdered milk, powdered sugar, vitamins, and minerals, combined in a foil pouch. Each $92 \mathrm{~g}$ pack provides $500 \mathrm{kcal}$ or $2.1 \mathrm{MJ}$. Plumpy'nut contains vitamins A, B-complex, C, D, E, and $\mathrm{K}$, and minerals calcium, phosphorus, potassium, magnesium, zinc, copper, iron, iodine, sodium, and selenium (Anabwanivario, 2005).

\subsubsection{Applications of RUTF}

The New York Times reported that the paste is administered in 500 kilocalories $(2.1 \mathrm{MJ})$ packets, twice daily, for two to four weeks, in combination with Unimix, a vitamin-enriched flour for making porridge, and will reverse malnutrition in severely malnourished children (Timbo and Tollefson, 1994).

The World Health Organization has recognized the utility of this food for famine relief. Plumpy'nut can be packaged in local peanut-producing areas, such as Malawi and Niger, by mixing the groundnut and milk paste with a slurry of vitamins and minerals from Nutriset. Médecins Sans Frontières (also known as Doctors without Borders) has been dispensing 14 packets (one week's worth) of Plumpy'nut in 22 centers in Niger since May 2005, but only to those children who are dramatically underweight and sufficiently well to benefit from outpatient care. Project Peanut Butter has done extensive field trials with RUTF in Malawi from 2001-2007, operating the first local factory where Plumpy'nut is produced, and distributing this therapeutic food to malnourished Malawian children in more than 20 nutritional rehabilitation centers (Ott, et al., 1993). 


\subsubsection{RUTF mechanism of action}

Plumpy'nut is frequently used as a treatment for emergency malnutrition cases. It helps with rapid weight gain, which can make the difference between life and death for a young child. The product is also easy for children to eat since they can feed themselves the soft paste. The fortified peanut butter-like paste contains a balance of fats, carbohydrates, and proteins (macronutrients), and vitamins and minerals (micronutrients). Peanuts contain mono-unsaturated fats, which are easy to digest. They are also very high in calories, which means that a child will get a lot of energy from just small amounts, important because malnutrition shrinks the stomach. They are rich in zinc and protein - both good for the immune system, and protein is needed for muscle development. Peanuts are also a good source of vitamin E, an antioxidant that helps to convert food into energy.

\subsubsection{Cost of RUTF}

A standard Plumpy'nut treatment goes for four weeks (two to three times a day) at a cost of 12 Euros in Africa. The cost for four weeks of Plumpy'nut and Unimix is $\$ 35$ per child. The cost in Haiti for a similar RUTF peanut butter-based product is a bit higher, but still relatively inexpensive.

\subsection{Previous studies about RUTF}

In 2007 in Nyanza Province in Kenya, Médecins Sans Frontières (MSF) enrolled HIV positive adults from a large Ministry of Health (MOH) /MSF HIV program into a nutritional program. The purpose of this was to study the acceptability of peanut-based Ready to Use Therapeutic Food (RUTF) to HIV+ adults and any issues that arise from its distribution and consumption. A total of 56 patients and eight MOH/MSF staff were involved in the study. The patients were all taking antiretroviral therapy (ARV), had a Body Mass Index (BMI) < 17 and/or Mid Upper Arm Circumference (MUAC) <185 and/ or oedema. They received four sachets of a peanut-based RUTFdaily (energy equivalent 2,000 kcals/day). The research team used qualitative methods such as key informant interviews, focus groups, and direct unobtrusive observations. This study suggests that an improved approach to treating malnourished HIV+ adults living in resourcepoor settings is needed. This approach must take into consideration the differences that exist between the traditional outpatient program designed for children and the challenging reality of malnourished adults, including the need for a novel RUTF specifically designed for malnourished adults with HIV (Dibari, et al., 2008).

A controlled, comparative, clinical effectiveness trial was conducted in southern Malawi with 1178 malnourished children. Children were systematically allocated to either standard therapy (186 children) or home-based therapy with RUTF (992 children) according to a stepped wedge design to control for bias introduced by the season of the year. Recovery, defined as reaching a weight-for-height $z$ score -2, and relapse or death were the primary outcomes. The rate of weight gain and the prevalence of fever, cough, and diarrhea were the secondary outcomes. Children who received home-based therapy with RUTF were more likely to achieve a weight-for-height $z$ score- 2 than were those who received standard therapy $(79 \%$ compared with $46 \%$; $P$ - 0.001) and were less likely to relapse or die (8.7\% compared with $16.7 \%$; $P$ - 0.001). Children who received home-based therapy with RUTF had greater rates of weight gain (3.5 compared with $2.0 \mathrm{~g} \cdot \mathrm{kg}-1 \cdot \mathrm{d}-1$; difference: $1.5 ; 95 \% \mathrm{CI}: 1.0,2.0 \mathrm{~g} \cdot \mathrm{kg}$ $1 \cdot \mathrm{d}-1)$ and a lower prevalence of fever, cough, and diarrhea than did children who received standard therapy (Michael, et al., 2005).

An experimental laboratory, a based study has been conducted in Khartoum state during the period from July 2008 to November 2009. The study objectives: was to test manufactured Ready To Use Therapeutic Food (RUTF) in relation to locally produced RUTF (groundnuts and sesame pastes). Manufactured RUTF and local samples (groundnuts and sesame pastes) brought from Khartoum State markets, which treated with different flavors and undergone to roasting, then sensory evaluation and approximate chemical and physical analysis were done in Ahfad University Laboratory. Results showed that treated samples of RUTF (ground and sesame paste samples) significantly different from control RUTF samples (P-value $\leq 0.05$ ) (Abd-AL-Salam and Ahmed, 2009).

A total sample of one hundred and fifty under-five children was taken from both locations. The study aimed to evaluate the effectiveness of communitybased therapeutic feeding compared to facility-based therapeutic feeding for severely malnourished $<5$ years old children in North Darfur State during 2004 in terms of discharge rate, default rate, death rate, and program coverage. The main finding of the study showed that the discharge rate according to criteria, in Tawila was $55.7 \%$ while in Elfasher hospital was $73.2 \%$. The defaulters' rate was $6.9 \%$ in Tawila and $21.8 \%$ at Elfasher hospital. There were only two deaths among children that occurred in Elfasher hospital while no case in Tawila OTP as the majority of severely malnourished children was referred from Tawila SC to Elfasher hospital. These findings reflect that the community-based approach helps to facilitate identification of the malnourished children and 
probably reduces the defaulters' rates. While the hospital-based approach is more efficient in terms of treatment and follows up of malnourished children that allow early discharge and improvement. Moreover, the feeding system is more organized and regular in the hospital that has a good impact on children nutrition status unlike those at the household level where the phenomenon of food sharing is quite common. In addition to immediate health care if children are outside the feeding center (Abdalla, 2009).

\section{Methodology}

\subsection{Study design}

This study is an observational "before and after" randomized controlled trial study, using routinely collected data. It is not clinical research as such, but a description of outcomes following the introduction of RUTF and nutrition counseling. The selected participants (patients) were divided into two groups, case, and control group. Both groups were given nutritional counseling and only the control group was given the RUTF.

\subsection{Study area}

This study was conducted in Omdurman VCT Center at Omdurman Teaching Hospital, which recently established in the year 2004. In the beginning, the center started the provision of counseling and investigation services to HIV/Patients. By the year 2005, the center started treatment services in addition to previous ones for the patients. The total number of HIV/AIDS patients who attending for counseling and investigation ranged between $5-7$ patients per day, those who attend for voluntary testing for HIV about 20 - 25 individuals per day, while the number of HIV/AIDS patients attending for ARV ranged between 20 - 30 patients per day.

The Staff of the VCT Center:

The VCT center consisted of the following staff:

$$
\begin{array}{ll}
\text { - } & \text { Dr. Osama AwadSalih } \\
\text { - } & \text { Dr. Mohammed Osman Hamed } \\
\text { - } & \text { Dr. Omer Nemiri } \\
\text { - } & \text { Dr. Mutaz }
\end{array}
$$

\subsection{Study population}

All the patients who live with HIV/AIDS who attended Omdurman VCT Center for routine check-up, treatment and counseling.

\subsection{Sampling}

A total of 7 HIV patients were selected from those who attending Omdurman VCT Center at Omdurman Teaching Hospital during the conduction of the study.
The basic criteria used for selection of the study subject were:

- HIV/AIDS patient.

- His/her BMI indicates malnutrition.

- Accepted to participate in the study.

- Regularly attending Omdurman VCT Center at Omdurman Teaching Hospital.

\subsubsection{Sample Selection Procedure}

The first step was securing the permissions for using the VCT center at Omdurman Teaching Hospital, this step took a quiet time of continuous communication and discussions.

Patients used to attend at the VCT Center on Monday and Wednesday for $\mathrm{CD}_{4}$ investigation. During these days orientation sessions were held by the researcher for explaining the purpose and protocol of the study to the patients, patients were given full choice whether to participate or not in the study. Other issues were also explained to patients such as the importance of food for drugs maximum use, which accepted by some patients as thought it to be an alternative to treatment and free of charge. However, it was made clear that this meal (RUTF) is not an alternative to drug. A preparatory meeting was held between the different partners involved in the research including, research, principal investigator, co-investigators (Director of the VCT), representative of the Federal Ministry of Health and staff of the VCT at the Omdurman Teaching Hospital. The meeting agreed on the study protocol and steps forward for conducting the research, the ethical consideration regarding dealing with patients and saving guard the patient's information.

The research team attended a workshop prepared by the Sudan National AIDS Program (SNAP) about communication with people living with HIV/AIDS, the effects of ARV and the effects of other drugs that may cause anemia and obesity.

\subsubsection{Sample Selection}

From the visits conducted to the VCT center and after the orientation sessions about 42 patients agreed to join the study. Each patient contacted individually through telephone to determine a date for taking his/her BMI. Out of the total number (22) registered only 7 were found to have low BMI (entry criteria).

\subsection{Material}

The material (RUTF) was provided through permission from the UNICEF and AL Manar Organization. One Hundred Carton of the RUTF was kept in a store for keeping its quality as recommended by the factory. 


\subsection{Data collection}

\subsubsection{Primary data}

Primary data was collected directly from HIV patients who attended Omdurman VCT Center at Omdurman Teaching Hospital using a questionnaire including demographic characteristics (age, gender, education, tribe, residence, occupation and marital status) as well as questions to obtain information about the current health status of the patients, weight and height as well as anthropometric measurements (BMI and MUAC) in addition to basic information about medications, nutrition and complications.

The second tool for data collection used was a check list to record weight changes during intake of food regimen (RUTF).

\subsubsection{Secondary data}

Secondary data was collected from different books, journals, the internet and published related researches and reports.

\subsection{Data analysis}

A master coding sheet was designed using Microsoft Excel. Then the data obtained from the questionnaire, BMI and recorded weights were discharged to be manipulated by Statistical Packages for Social Sciences (SPSS). Paired Sample T-Test was used to determine the significant differences between the mean average weights between the control and patient groups. The Statistical Package for Social Science (SPSS) version used here was 12.0.

\subsection{The study duration}

This study was conducted during the period from September 2008 to March 2009.

\section{Results}

This chapter concerns the findings of the computerized analysis that been carried out for the questionnaires and the data had been collected through anthropometric measurements and direct interview with the respondents.

\subsection{General Characteristics of the Study Population}

Table (4.1) Basic Information about the patient

\begin{tabular}{|c|c|c|c|}
\hline Indicators & Response & Frequency (n) & Percent (\%) \\
\hline \multirow[t]{2}{*}{ Age (Years) } & $20-30$ years & 2 & $28.6 \%$ \\
\hline & $31-40$ years & 5 & $71.4 \%$ \\
\hline \multirow[t]{2}{*}{ Gender } & Male & 5 & $71.4 \%$ \\
\hline & Female & 2 & $28.6 \%$ \\
\hline \multirow[t]{3}{*}{ Tribe } & Western & 4 & $57.1 \%$ \\
\hline & Northern & 1 & $14.3 \%$ \\
\hline & Central & 2 & $28.6 \%$ \\
\hline \multirow[t]{7}{*}{ Residence } & Dar Elsalam - Libya Market & 1 & $14.3 \%$ \\
\hline & Wad Rawa City in Elgazera & 1 & $14.3 \%$ \\
\hline & Ombada Squire 33 & 1 & $14.3 \%$ \\
\hline & Bahri - HilatKhojali & 1 & $14.3 \%$ \\
\hline & Elthawra Squire 11 & 1 & $14.3 \%$ \\
\hline & GabalAwlia & 1 & $14.3 \%$ \\
\hline & Elthawra Squire 59 & 1 & $14.3 \%$ \\
\hline
\end{tabular}


As shown in Table (4.1) the majority of the patients (71.4\%) were in the age group 31 - 40 years, while gender distribution showed that $71.4 \%$ of them were males and the remainder $28.6 \%$ were females. Most of the respondents $(57.1 \%)$ belonged to Western tribes, $28.6 \%$ to Central tribes and $14.3 \%$ to Northern tribes. The respondents distributed equally to seven residential areas in Khartoum state.

Table (4.2) Education, occupation, marital status, and family size

\begin{tabular}{|c|c|c|c|}
\hline Indicators & Response & Frequency (n) & Percent (\%) \\
\hline \multirow{4}{*}{$\begin{array}{l}\text { Level of education of the } \\
\text { patient }\end{array}$} & Khalwa & 2 & $28.6 \%$ \\
\hline & Primary & 2 & $28.6 \%$ \\
\hline & Secondary & 2 & $28.6 \%$ \\
\hline & Illiterate & 1 & $14.3 \%$ \\
\hline \multirow{3}{*}{$\begin{array}{l}\text { Marital status of the } \\
\text { patient }\end{array}$} & Single & 4 & $57.1 \%$ \\
\hline & Married & 2 & $28.6 \%$ \\
\hline & Widowed & 1 & $14.3 \%$ \\
\hline \multirow[t]{4}{*}{ Occupation of the patient } & Laborer & 2 & $28.6 \%$ \\
\hline & Housewife & 1 & $14.3 \%$ \\
\hline & Left the work & 1 & $14.3 \%$ \\
\hline & Free business & 3 & $42.9 \%$ \\
\hline \multirow[t]{3}{*}{ Number of family members } & $<5$ & 4 & $57.1 \%$ \\
\hline & $5-8$ & 2 & $28.6 \%$ \\
\hline & $>8$ & 1 & $14.3 \%$ \\
\hline
\end{tabular}

Socioeconomic characteristics of the respondents are shown in Table (4.2). The highest level the respondents (28.6\%), have had secondary education and the same percentage of them have Khalwa and primary level, and $14.3 \%$ were found to be illiterate. 
Most of the respondents (57.1\%) as indicated in Table (4.2) were married and $14.3 \%$ of them were widowed. Occupational status showed that the highest percentage of the respondents $(42.9 \%)$ free business, $28.6 \%$ of them were laborers.

Table (4.3) Wight, height and anthropometry

\begin{tabular}{|c|c|c|c|}
\hline Indicators & Response & Frequency (n) & Percent (\%) \\
\hline \multirow[t]{3}{*}{ Patient starting weight } & $<40 \mathrm{~kg}$ & 1 & $14.3 \%$ \\
\hline & $40-50 \mathrm{~kg}$ & 5 & $71.4 \%$ \\
\hline & $>50 \mathrm{~kg}$ & 1 & $14.3 \%$ \\
\hline \multirow[t]{2}{*}{ Final weight } & $40-50 \mathrm{~kg}$ & 5 & $71.4 \%$ \\
\hline & $>50 \mathrm{~kg}$ & 2 & $28.6 \%$ \\
\hline \multirow[t]{3}{*}{ Height of the patient } & $<150 \mathrm{~cm}$ & 1 & $14.3 \%$ \\
\hline & $150-160 \mathrm{~cm}$ & 4 & $57.1 \%$ \\
\hline & $161-170 \mathrm{~cm}$ & 2 & $28.6 \%$ \\
\hline Patients' MUAK (cm) & $18-25 \mathrm{~cm}$ & 7 & $100.0 \%$ \\
\hline \multirow[t]{2}{*}{ Patient's BMI } & $<18$ & 2 & $28.6 \%$ \\
\hline & $18-25$ & 5 & $71.4 \%$ \\
\hline
\end{tabular}

The average initial reported weight of the majority of the respondents was found to be ranged between 40 $50 \mathrm{~kg}$, the same percentage, and the same average were reported for the respondents as a final weighed. The average height of most of the respondents (57.1\%) was found to be raged between $150-160 \mathrm{~cm}$.
Most of the respondent's families (57.1\%) have less than five members per family, and $14.3 \%$ have more than 8 members. 
Table (4.4) Complaining tuberculosis and any other opportunistic diseases

\begin{tabular}{|c|c|c|c|}
\hline Indicators & Response & Frequency (n) & Percent (\%) \\
\hline \multirow[t]{2}{*}{ Tuberculosis } & Yes & 4 & $57.1 \%$ \\
\hline & No & 3 & $42.9 \%$ \\
\hline \multirow[t]{2}{*}{ Skin rash } & Yes & 2 & $28.6 \%$ \\
\hline & No & 5 & $71.4 \%$ \\
\hline \multirow[t]{2}{*}{ Fever } & Yes & 1 & $14.3 \%$ \\
\hline & No & 6 & $85.7 \%$ \\
\hline \multirow[t]{2}{*}{ Joint pain } & Yes & 1 & $14.3 \%$ \\
\hline & No & 6 & $85.7 \%$ \\
\hline \multirow[t]{2}{*}{ Colon } & Yes & 1 & $14.3 \%$ \\
\hline & No & 6 & $85.7 \%$ \\
\hline \multirow[t]{2}{*}{ Anemia } & Yes & 1 & $14.3 \%$ \\
\hline & $\mathrm{No}$ & 6 & $85.7 \%$ \\
\hline \multicolumn{4}{|c|}{$\begin{array}{l}\text { As shown by the findings in Table (4.4) the most } \\
\text { common opportunistic infection associated with } \\
(28.6 \%) \text {, fever }(14.3 \%) \text {, the se } \\
\text { HIV/AIDS among the respondents was found to be } \\
\text { tuberculosis, which complained by } 57.1 \% \text { of them. } \\
\text { Table (4.5) Loss of appetite and symptoms of HIV/AIDS }\end{array}$} \\
\hline Indicators & Response & Frequency (n) & Percent (\%) \\
\hline \multirow[t]{2}{*}{ Loss of appetite } & $Y e s$ & 5 & $71.4 \%$ \\
\hline & No & 2 & $28.6 \%$ \\
\hline \multirow[t]{2}{*}{ Diarrhoea } & Yes & 2 & $28.6 \%$ \\
\hline & $\mathrm{No}$ & 5 & $71.4 \%$ \\
\hline \multirow[t]{2}{*}{ Common cold } & Yes & 1 & $14.3 \%$ \\
\hline & $\mathrm{No}$ & 6 & $85.7 \%$ \\
\hline Weight loss & Yes & 7 & $100.0 \%$ \\
\hline
\end{tabular}

Table (4.5) shows that the majority of the HIV patients in this study (71.4\%) complained loss of appetite, all of them complained weight loss, $28.6 \%$ diarrhea, and $14.3 \%$ said common cold. 
Table (4.6) HIV/AIDS medications

\begin{tabular}{|c|c|c|c|}
\hline Indicators & Response & Frequency (n) & Percent (\%) \\
\hline Type of drug & Pre ARV & 5 & $71.4 \%$ \\
\hline \multirow{2}{*}{$\begin{array}{l}\text { Period of starting the } \\
\text { medicines }\end{array}$} & 6 month - 1 year & 3 & $42.9 \%$ \\
\hline & More than 1 year & 2 & $28.5 \%$ \\
\hline \multirow{2}{*}{$\begin{array}{l}\text { Availability of drug and food } \\
\text { interaction or problems }\end{array}$} & Yes & 1 & $14.3 \%$ \\
\hline & $\mathrm{No}$ & 6 & $85.7 \%$ \\
\hline $\begin{array}{l}\text { The type of interaction or } \\
\text { problem }\end{array}$ & Nausea & 1 & $14.3 \%$ \\
\hline $\begin{array}{l}\text { If the patient that food is an } \\
\text { important factor in the } \\
\text { prevention of HIV/AIDS }\end{array}$ & Yes & 7 & $100.0 \%$ \\
\hline \multicolumn{4}{|c|}{ 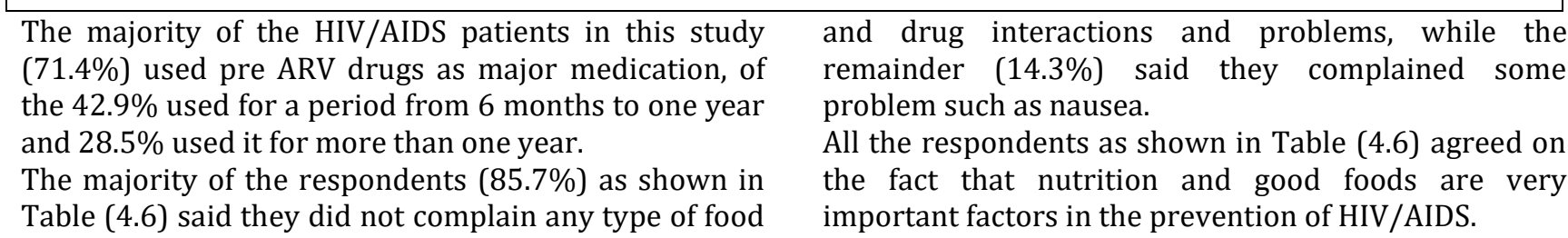 } \\
\hline
\end{tabular}

Table (4.7) Some food items intake patterns (breakfast)

\begin{tabular}{|c|c|c|c|}
\hline Indicators & Response & Frequency (n) & Percent (\%) \\
\hline \multirow[t]{3}{*}{ Foul } & Daily & 5 & $71.4 \%$ \\
\hline & Twice a week & 1 & $14.3 \%$ \\
\hline & Once each two weeks & 1 & $14.3 \%$ \\
\hline \multirow[t]{3}{*}{ Lentil } & Daily & 1 & $14.3 \%$ \\
\hline & Twice a week & 4 & $57.1 \%$ \\
\hline & Once each two weeks & 2 & $28.6 \%$ \\
\hline \multirow[t]{2}{*}{ Egg } & Twice a week & 2 & $28.6 \%$ \\
\hline & Once each two weeks & 2 & $28.6 \%$ \\
\hline
\end{tabular}




\begin{tabular}{|c|c|c|c|}
\hline & Once each month & 1 & $14.3 \%$ \\
\hline & Never & 2 & $28.6 \%$ \\
\hline \multirow[t]{4}{*}{ Yogurt } & Daily & 2 & $28.6 \%$ \\
\hline & Twice a week & 2 & $28.6 \%$ \\
\hline & Once each month & 1 & $14.3 \%$ \\
\hline & Never & 2 & $28.6 \%$ \\
\hline \multirow[t]{3}{*}{ Jam } & Twice a week & 1 & $14.3 \%$ \\
\hline & Once each month & 2 & $28.6 \%$ \\
\hline & Never & 4 & $57.1 \%$ \\
\hline \multirow[t]{3}{*}{ Asida + mulah } & Daily & 4 & $57.1 \%$ \\
\hline & Twice a week & 1 & $14.3 \%$ \\
\hline & Never & 2 & $28.6 \%$ \\
\hline Bread & Daily & 7 & $100.0 \%$ \\
\hline \multirow[t]{3}{*}{ Kisra + Mulah } & Daily & 2 & $28.6 \%$ \\
\hline & Twice a week & 1 & $14.3 \%$ \\
\hline & Never & 4 & $57.1 \%$ \\
\hline \multirow[t]{2}{*}{ Milk } & Twice a week & 2 & $28.6 \%$ \\
\hline & Never & 5 & $71.4 \%$ \\
\hline
\end{tabular}

The more frequent food item consumed by the respondents in breakfast was found to be broad bean (foul), which consumed daily by $71.4 \%$ of the respondents, followed by asida and mulah (57.1\%),
Kisra and mulah (28.6\%) and the same percentage was reported by milk and yogurt as less frequent foods eaten by the respondents on daily basis (Table 4.7). 


\begin{tabular}{|c|c|c|c|}
\hline Indicators & Response & Frequency (n) & Percent (\%) \\
\hline \multirow[t]{2}{*}{ Mulah } & Daily & 5 & $71.4 \%$ \\
\hline & Twice a week & 2 & $28.6 \%$ \\
\hline \multirow[t]{2}{*}{ Soup } & Daily & 1 & $14.3 \%$ \\
\hline & Twice a week & 6 & $85.7 \%$ \\
\hline \multirow[t]{3}{*}{ Salad } & Daily & 2 & $28.6 \%$ \\
\hline & Twice a week & 3 & $42.9 \%$ \\
\hline & Once each month & 2 & $28.6 \%$ \\
\hline \multirow[t]{5}{*}{ Rice } & Daily & 1 & $14.3 \%$ \\
\hline & Twice a week & 3 & $42.9 \%$ \\
\hline & Once each two weeks & 1 & $14.3 \%$ \\
\hline & Once each month & 1 & $14.3 \%$ \\
\hline & Never & 1 & $14.3 \%$ \\
\hline \multirow[t]{3}{*}{ Chicken } & Twice a week & 1 & $14.3 \%$ \\
\hline & Once each month & 4 & $57.1 \%$ \\
\hline & Never & 2 & $28.6 \%$ \\
\hline \multirow[t]{3}{*}{ Meat } & Daily & 3 & $42.9 \%$ \\
\hline & Once each two weeks & 1 & $14.3 \%$ \\
\hline & Never & 3 & $42.9 \%$ \\
\hline
\end{tabular}

The patterns of food intake in lunch by the respondents are shown in Table (4.8). Mulah was found to be more frequent food item consumed daily by $71.4 \%$ of the respondents, followed by meat which consumed daily by $42.9 \%$ of the respondents, salad which was eaten by $28.6 \%$ of the respondents, and rice which was consumed daily by $14.3 \%$. The chicken was found to be less frequent food item consumed by $14.3 \%$ of the respondents twice a week.

Table (4.9) Some food items intake patterns (dinner)

\begin{tabular}{|l|c|c|c|}
\hline \multicolumn{2}{|c|}{ Indicators } & Response & Frequency (n) \\
\hline \multirow{2}{*}{ Foul } & Daily & 3 & $42.9 \%$ \\
\cline { 2 - 4 } & Never & 4 & $57.1 \%$ \\
\hline \multirow{2}{*}{ Total } & & 7 & $100.0 \%$ \\
\hline & Daily & 1 & $14.3 \%$ \\
\hline \multirow{2}{*}{ Total } & Never & 6 & $85.7 \%$ \\
\hline \multirow{2}{*}{ Egg } & & 7 & $100.0 \%$ \\
\hline Total & Daily & 1 & $14.3 \%$ \\
\hline \multirow{2}{*}{ Yogurt } & Never & 6 & $85.7 \%$ \\
\cline { 3 - 4 } & & 7 & $100.0 \%$ \\
\hline
\end{tabular}




\begin{tabular}{|c|c|c|c|}
\hline \multicolumn{2}{|l|}{ Total } & 7 & $100.0 \%$ \\
\hline \multirow[t]{2}{*}{ Jam } & Twice a week & 1 & $14.3 \%$ \\
\hline & Never & 6 & $85.7 \%$ \\
\hline \multicolumn{2}{|l|}{ Total } & 7 & $100.0 \%$ \\
\hline \multirow[t]{2}{*}{ MadiaHelba } & Daily & 4 & $57.1 \%$ \\
\hline & Never & 3 & $42.9 \%$ \\
\hline \multicolumn{2}{|l|}{ Total } & 7 & $100.0 \%$ \\
\hline \multirow[t]{3}{*}{ Custard } & Daily & 2 & $28.6 \%$ \\
\hline & Twice a week & 1 & $14.3 \%$ \\
\hline & Never & 4 & $57.1 \%$ \\
\hline \multicolumn{2}{|l|}{ Total } & 7 & $100.0 \%$ \\
\hline \multirow[t]{3}{*}{ Milk } & Daily & 2 & $28.6 \%$ \\
\hline & Twice a week & 1 & $14.3 \%$ \\
\hline & Never & 4 & $57.1 \%$ \\
\hline \multicolumn{2}{|l|}{ Total } & 7 & $100.0 \%$ \\
\hline \multirow[t]{2}{*}{ Asida + milk } & Twice a week & 2 & $28.6 \%$ \\
\hline & Never & 5 & $71.4 \%$ \\
\hline \multicolumn{2}{|l|}{ Total } & 7 & $100.0 \%$ \\
\hline
\end{tabular}

As shown in Table (4.9) madidahelba was the most frequent food item consumed by the respondents in dinner, which eaten daily by $57.1 \%$, followed by broad beans (foul) which eaten by $42.9 \%$ of the respondents,

then custard and milk which eaten by $28.6 \%$ of the respondents and finally egg was eaten daily by $14.3 \%$ of the respondents.

\subsection{Changes in the Patient's Weight during the Course of the Study}

Figure (4.1) reported weights of the patients

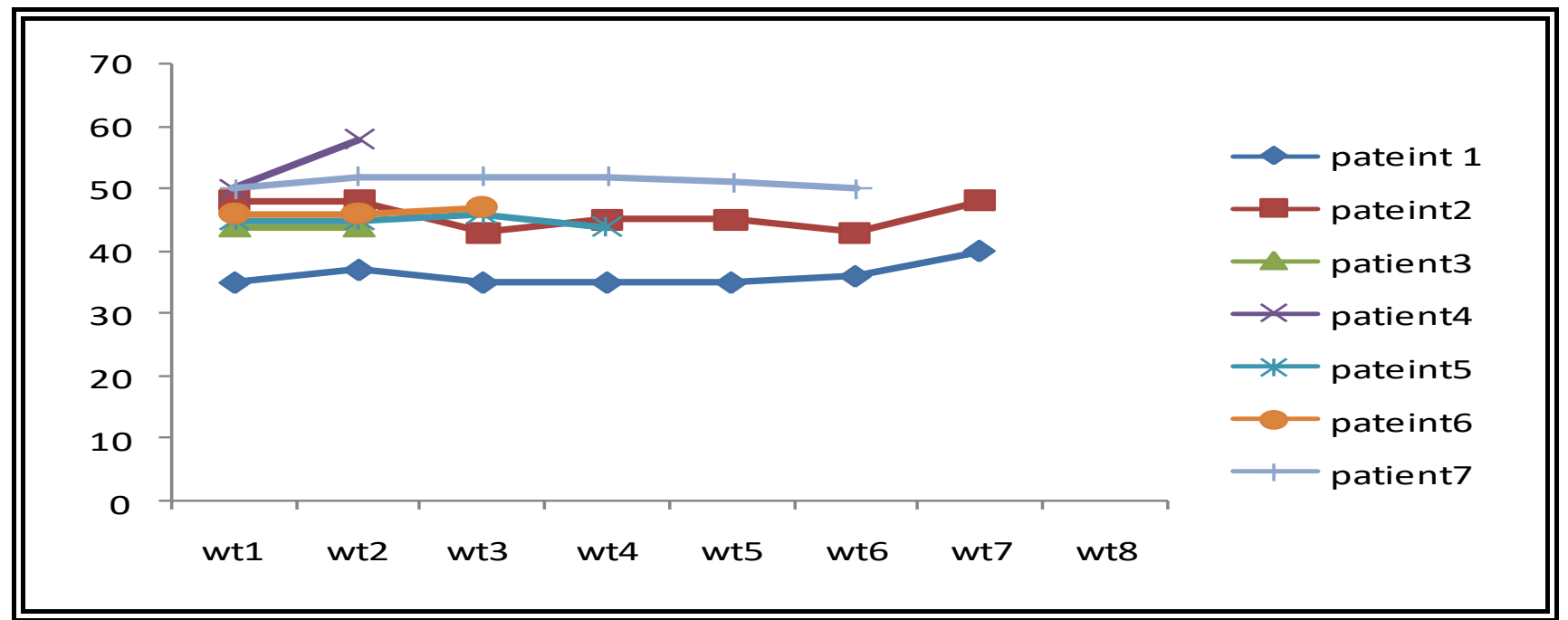

Figure (4.1) shows the reported weights of the patients during administration of RUTF ( 8 weeks). The overall record of weights showed fluctuation from initial reading to the final reading. However, the most pronounced observation was that none of the respondent reported a decline in their weight. Two of the respondents $(1,2)$ showed a remarkable increase in their weight from the start of the study and particularly during week 7 and week 8 . 


\subsection{Changes in the Individual Patient's Weight during the Course of the Study}

Figure (4.2) Reported weights for patient 1

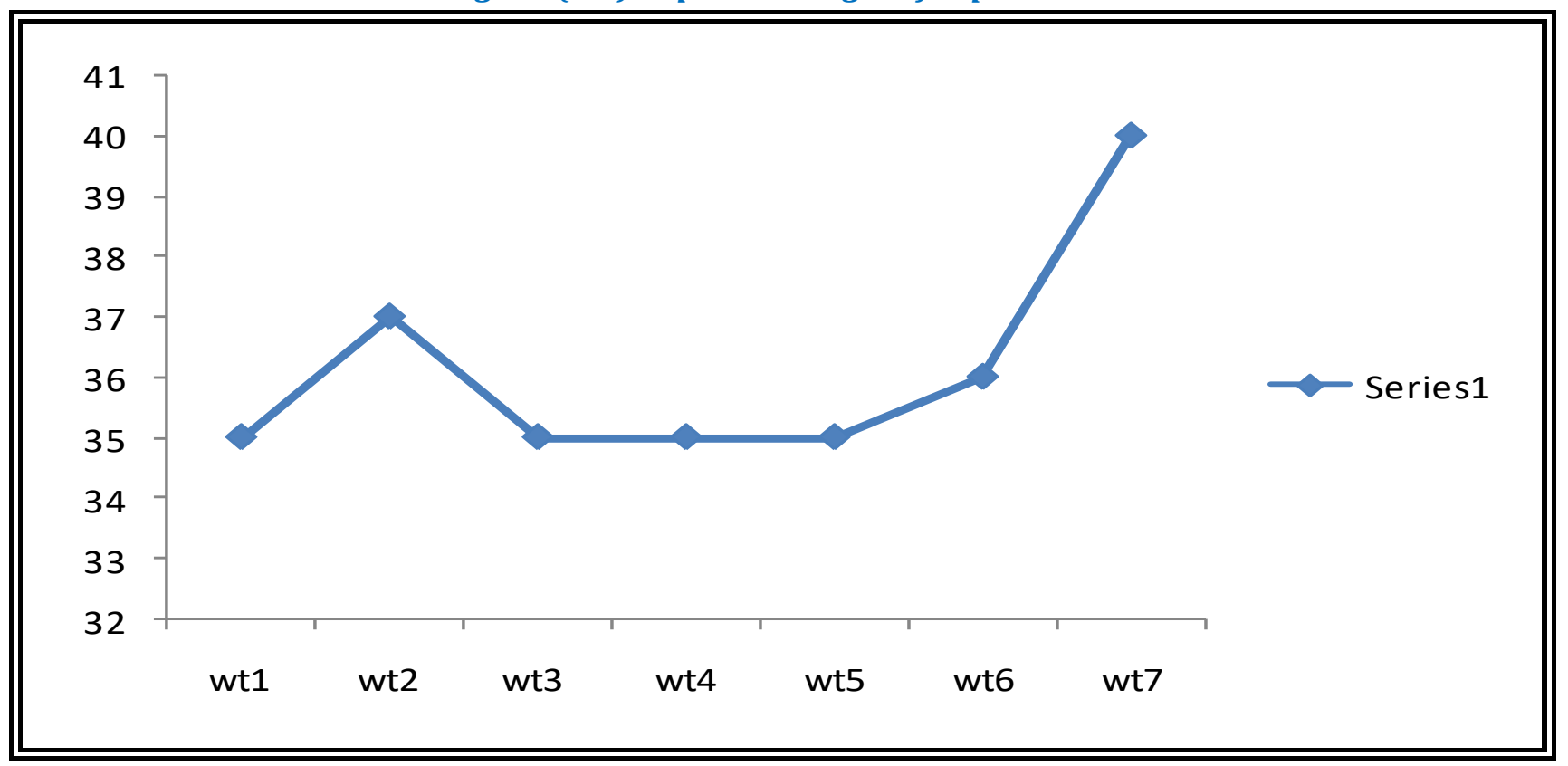

Weight curve of case 1 showed that there is an increase from the initial weight $(35 \mathrm{Kg})$ during the first week. During the following Two weeks, there was stabilization in the weight almost at the original weight (starting weight). The causes behind the decrease in the weight were because the patient was suffering from diarrhea and loss of appetite. As from week 5, 6 and 7 , the weight started to shoot up to reach a weight of $40 \mathrm{Kg}$, with a percent of increase about $42.8 \%$

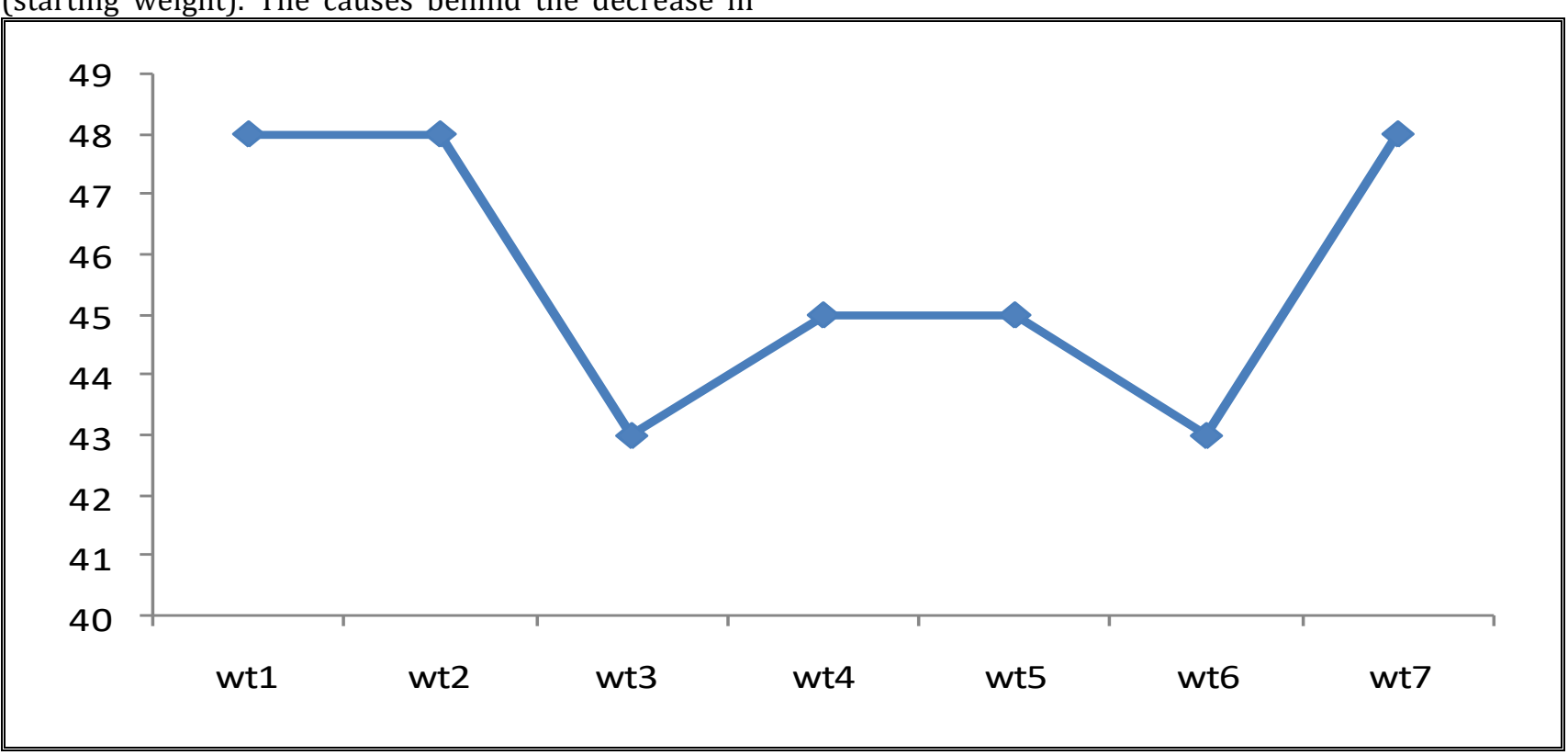




\section{Figure (4.3) Reported weight for patient 2}

Cases 2 as shown in Figure (4.3) showed constant weight from weight $1(48 \mathrm{~kg})$ to weight 2 , then dramatic decrease. By the $4^{\text {th }}$ reading an increase was recorded then the patient weight fixed till the $5^{\text {th }}$ reading and again decreased by the $6^{\text {th }}$ reading. The last reading showed increased weight, just as the initial weight. The patient complained of diarrhea, vomiting, malaria, loss of appetite and tuberculosis. These symptoms and infections may lead to loss of nutrients and thus cause the reported fluctuations in the patient weight.

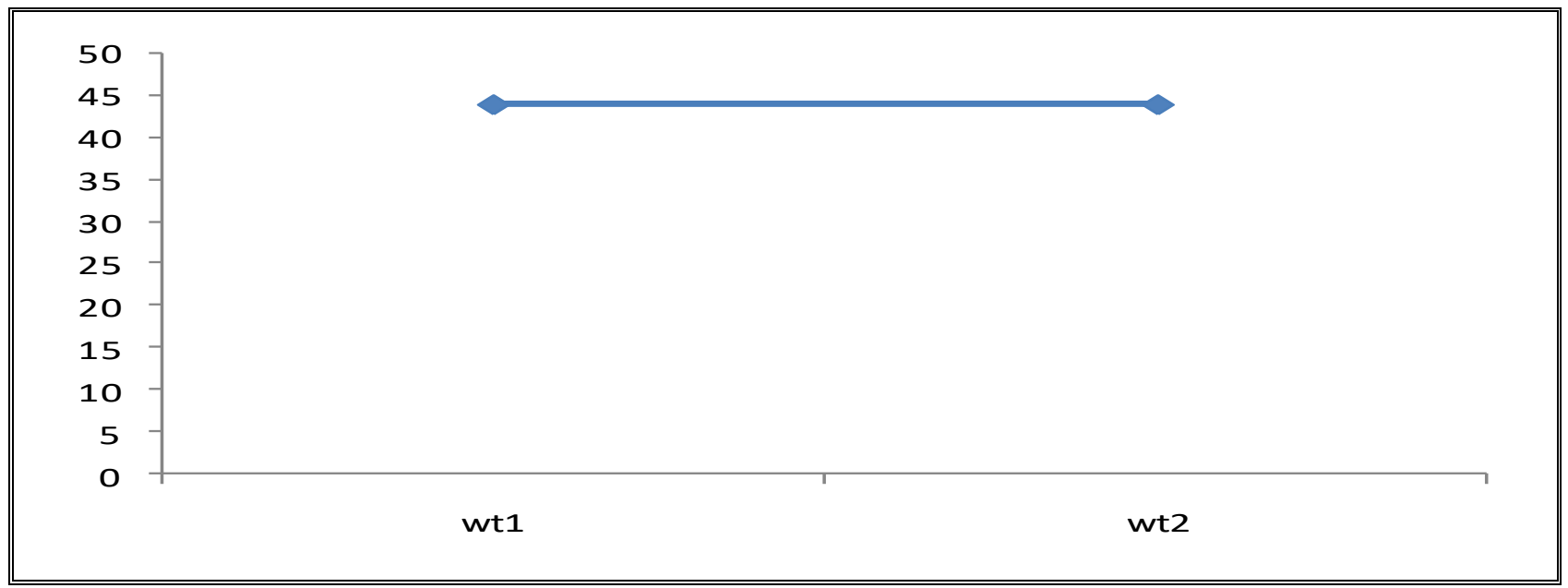

Figure (4.4) Reported weights for patient 3

For case 3 as indicated by Figure (4.4) only two and anemia, accordingly patient stopped the meal weights were reported, with no observed change. The patient suffering stomach pain, colon pain, colonists regimen.

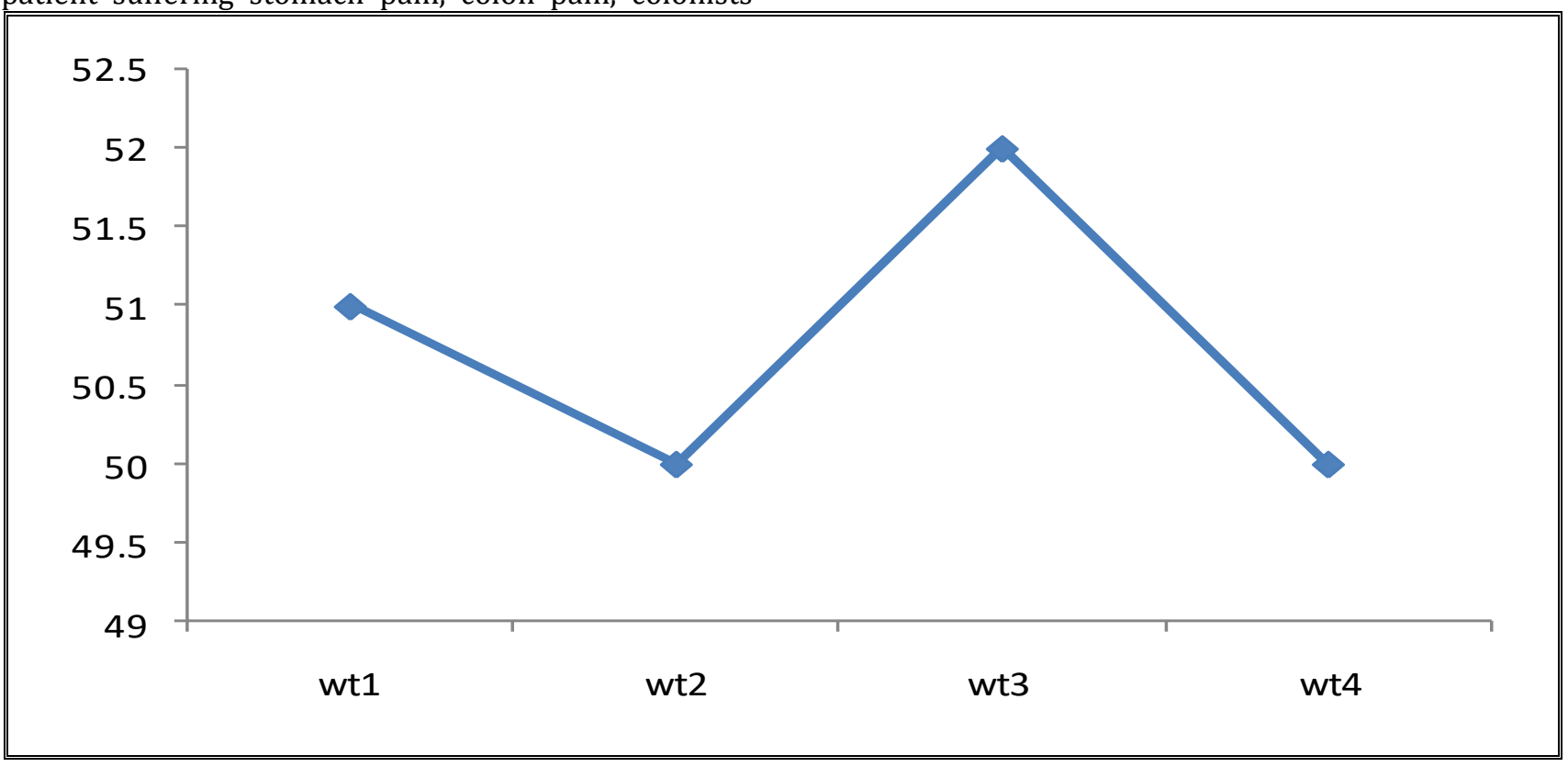




\section{Figure (4.5) Reported weight for patient 4}

Case 4 only reported increased weight at the $3^{\text {rd }}$ reading, then by the $4^{\text {th }}$ reading his weight prominently decreased. The patient suffering tuberculosis and stomachache with loss of appetite. The patient treated with intravenous solutions.

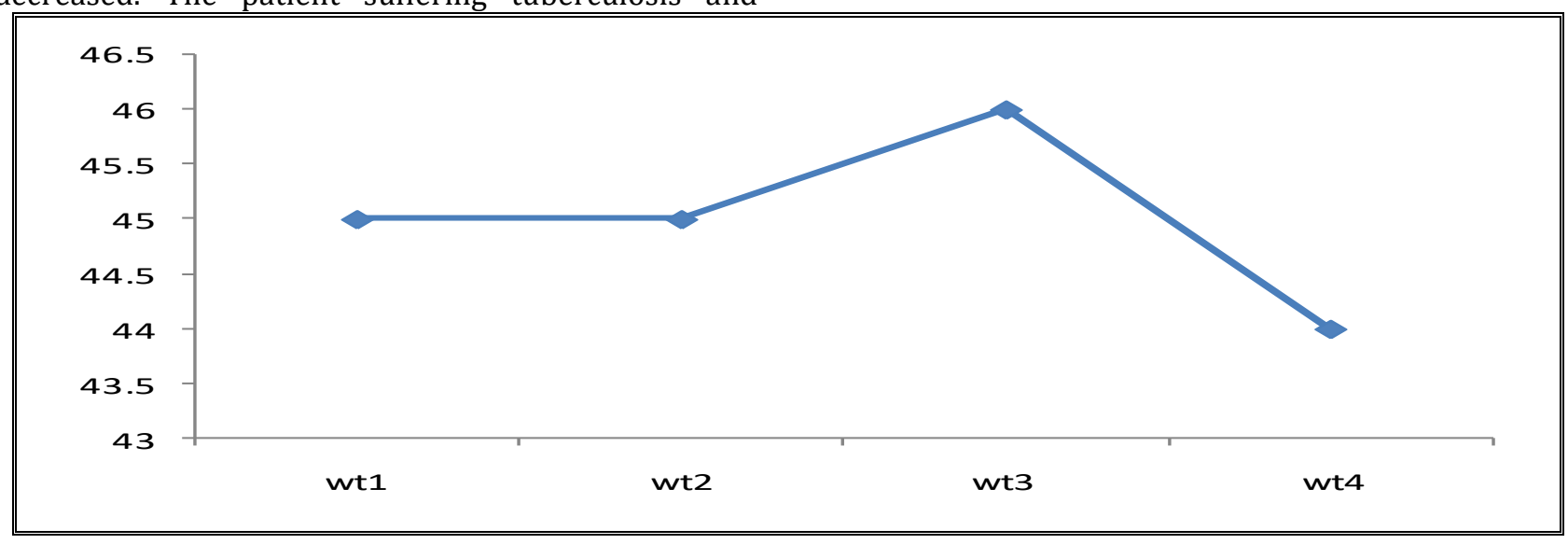

Figure (6) Reported weights for patient 5

Weight curve for case 5 shows decreased readings diarrhea and loss of appetite for a long period when he from initial to final weight. The patient suffering died before completing the regimen.

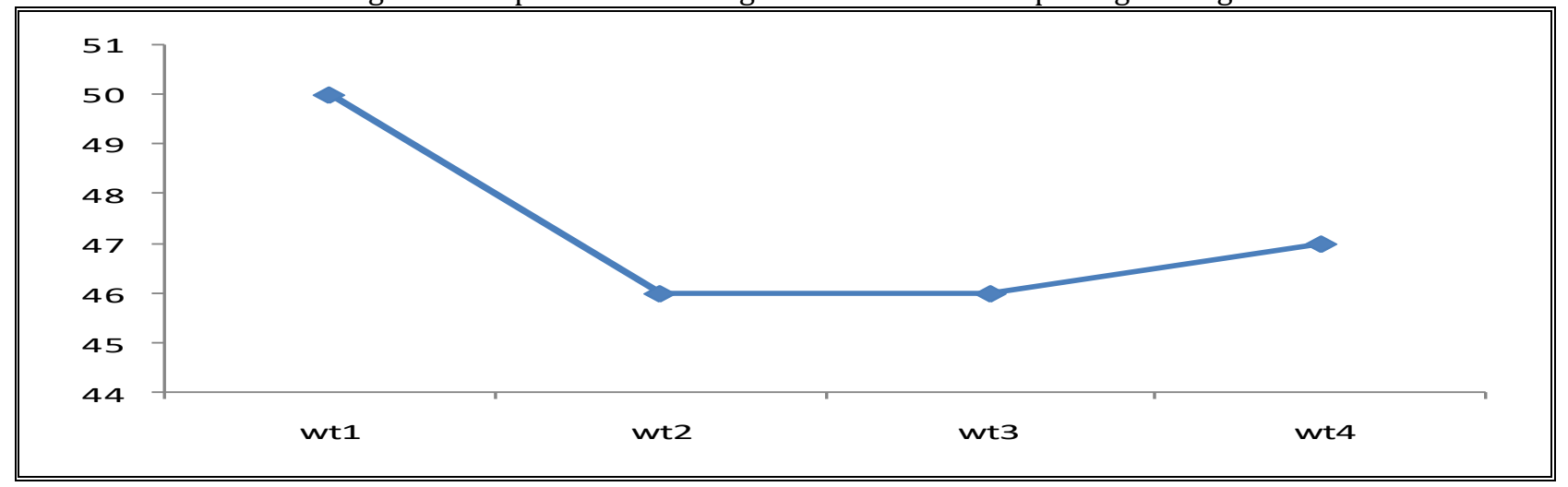

Figure (7) Reported weights for patient 6

Case 7 weights prominently decreased from the initial reading to $3^{\text {rd }}$ then his weight slightly increased by the $4^{\text {th }}$ reading. He escaped before completing the regimen.

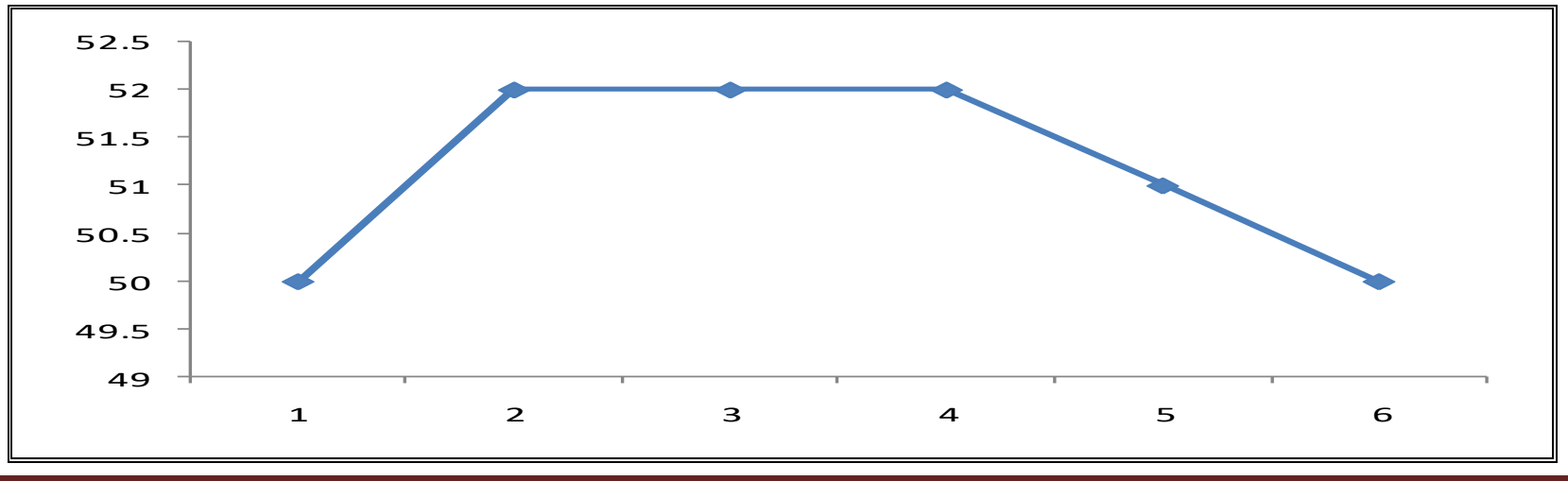

International Research in Medical and Health Sciences | Vol. 2 | Issue 3 | May- June| 2019

Page 28 


\section{Figure (4.8) Reported weights for patient 7}

The patient showed increased weight at the $2^{\text {nd }}$ reading then continued constantly until the $4^{\text {th }}$ reading and decreased again till the final reading. The patient complained of abdominal gas, loss of appetite and.

Table (4.10) Paired Sample T-test to compare median patients weights versus control median weights

\begin{tabular}{|l|c|c|c|c|}
\hline & Mean & N & Std. Deviation & $\begin{array}{c}\text { Salue } \\
\text { Sig. }\end{array}$ \\
\hline Patients median weights & 43.04 & 7 & \pm 5.69528 & 4.0 \\
\hline Control median weights & 59.85 & 7 & \pm 8.37871 & 0.007 \\
\hline
\end{tabular}

There is significant differences in mean weights between control and patients at the side of control ( $\mathrm{P}$ value $\leq 0.05$ ) at the confidential level (95\%).

As shown in Table (4.10) paired sample T-test showed that there are significant differences in median weights
Moreover, patient intake excessive amounts of coffee. Accordingly, these factors may affect the patient to get the benefits of the regimen (Figure 4.8).

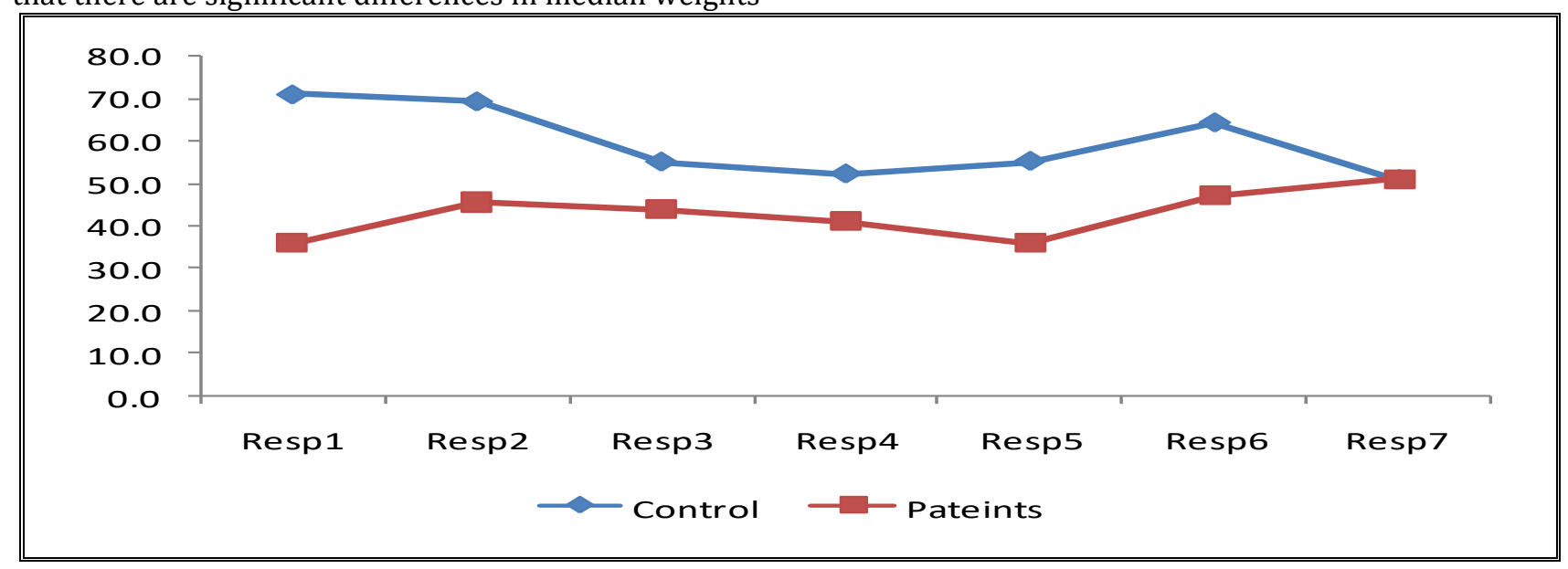

Figure (4.9) Comparison between reported mean weights of control and patients

Figure (4.9) showed the clear differences that reported between the mean weights of the patient and control group. It is clear from the figure, although the mean weights of the control group fall within relatively higher limits $(70-50 \mathrm{~kg})$, and the patient's weights within lower limits $(30-50 \mathrm{~kg})$, the overall progress of patients curve showed ascending pattern in contrast to control group weight curve.

\section{Discussion}

Concerning the personal, demographic and socioeconomic information about the respondents, results in Tables (4.1 and 4.2), showed that the majority of the patients $(71.4 \%)$ in the age group 31 40 years, which indicates that most of them in a sexually active age. Gender distribution showed that $71.4 \%$ of them were males and the remainder $28.6 \%$ were females. Males are more susceptible to acquire
HIV/AIDS infection than females, in that they have more freedom to make sexual relationships, thus they are commonly at the risk of HIV infection. According to data from a sentinel survey conducted by the Sudanese National AIDS Control Programme in 2004, HIV prevalence was estimated to be $1.0 \%$ among pregnant women, $2.3 \%$ among people with tuberculosis and 1.9\% among people with sexually transmitted infections (WHO, 2005b).

Socioeconomic characteristics of the respondents indicate the majority of them have low levels of education. The highest level the respondents have was found to be a secondary level (28.6\%), the same percentage of them have Khalwa and primary level. Thus, one may expect that the respondents have a low level of knowledge about the mode by which HIV can transmit and how to avoid the risky behaviors that may lead to getting HIV infection. Moreover, low level 
of education may cause the respondents to ignore the value of good nutrition and what are the required nutritional behaviors to be adopted for HIV/AIDS patients.

Economic conditions of the respondents in this study as indicated by the findings could be regarded as very difficult. Most of the respondents (57.1\%) were married, having marginal occupations that may not fulfill their livelihoods, and when recalling the time which spends by the respondents for treatment and in bed due to opportunistic infections, the negative effects on nutritional status of the respondents may increase. The findings as shown in Table (4.4) revealed that the most common opportunistic infection associated with HIV/AIDS among the respondents was found to be tuberculosis, skin rash, fever, joint pain, colon pain, and anemia. The majority of the HIV patients in this study (71.4\%) complained loss of appetite, all of them complained about weight loss, which some complication of diarrhea and the common cold. Opportunistic infections and diseases are common features among people living with HIV/AIDS.

The majority of the HIV/AIDS patients in this study (71.4\%) used pre ARV drugs as major medication, of the $42.9 \%$ used for a period from 6 months to one year and $28.5 \%$ used it for more than one year. ARV is the main treatment for HIV. Antiretroviral therapy improves nutritional status, but ARVs may also have side effects and metabolic complications. Highly active antiretroviral therapy (HAART) improves nutritional status, independent of its effects on viral suppression and immune status,33 although wasting still develops in some patients (Wanke, et al., 2000). The majority of the respondents $(85.7 \%)$ as shown in Table (4.6) said they did not complain any type of food and drug interactions and problems, while the remainder (14.3\%) said they complained some problem such as nausea. ARV interaction with nutrition is commonly occurring among HIV patients. ARV side effects such as nausea and vomiting may affect adherence to therapy, particularly in the first months of treatment (Chen, et al., 2003). Additional metabolic complications such as derangements in glucose and lipid metabolism, bone metabolism, and lactic academia have been associated with the use of certain ARV drugs (Shevitz and Knox, 2001).

All the respondents as shown in Table (4.6) agreed on the fact that nutrition and good foods are very important factors in the prevention of HIV/AIDS.

However, in most cases, the respondents consumed low nutritive foods. HIV-positive individuals require $10 \%$ more energy, and symptomatic HIV-positive individuals require $20 \%-30 \%$ more energy than HIV- negative individuals of the same age, sex, and physical activity level (WHO, 2003a).

The average initial reported weight of the majority of the respondents was found to be ranged between 40 $50 \mathrm{~kg}$, the same percentage, and the same average were reported for the respondents as a final weighed. All the patients MUAC was found to be between (18 25) $\mathrm{cm}$. The average Body Mass Index of the respondents (BMI) showed a relatively normal range (18 - 25) which was reported among $71.4 \%$ of the respondents, malnourished range (less than $18 \mathrm{BMI}$ ) was reported among $28.6 \%$ of the respondents. Moreover, as shown in Table (4.10) paired sample Ttest showed that there are significant differences in median weights between patients and control group. These difference were found to be on the side of the control group ( $\mathrm{P}$ value $\leq 0.05)$. On the other hand, Figure (4.9) showed clear differences that reported between the mean weights of the patient and control group. It is clear from the figure, although the mean weights of the control group fall within relatively higher limits $(70-50 \mathrm{~kg})$, and the patient's weights within lower limits (30 - 50 kg), the overall progress of patients curve showed ascending pattern in contrast to control group weight curve. These results indicate a considerable proportion of malnutrition among the respondents. Early studies demonstrated that weight loss and wasting were associated with increased risk of opportunistic infections (Wheeler, et al., 1998) and shorter survival time in HIV-positive adults, independent of their immune status (Suttmann, et al., 1995). Other studies showed that clinical outcome was poorer and risk of death was higher in HIV-positive adults with compromised micronutrient intake or status (Baum, et al., 1995; Tag, et al., 1996; Baum and Shor, 1998).

\section{Conclusions and Recommendations}

\section{6.1 Conclusions}

1. Food is an important component of growth and maintaining health. There is, however, a difference between energy requirement and a balanced diet. Both have to complement each other.

2. The food requirement for all people is divided into two large categories; macronutrients: carbohydrate, protein and fat; micronutrients: vitamins and minerals.

3. Generally, the reduced macronutrients intake can cause acute malnutrition and low energy and weakness, whereas the reduced intake of micronutrients can cause chronic malnutrition. 
4. Use of RUTF showed improvement effect on patients, where the findings showed that there are significant differences in median weights between patients and control group

5. Decrease of respondents' weights, could be attributed in some cases to complications caused by RUTF, death of some respondents and rejection of RUTF by others.

\subsection{Recommendations}

1. Patients must take their three meals and have at least two or three snacks; mid-morning, and mid-afternoon.

2. Each day, when it is possible, prepare and eat a variety and different types of animal and plant sources of protein: Animal source: poultry, fish, beef, egg, milk \& milk products Plant source: beans, peas, lentils, soybeans.

3. Add vegetable oil (preferably fortified with vitamins such as A, D \& E) to low energy carbohydrate food. (reduce oil consumption temporarily during the phase of diarrhea until the diarrhea is better).

4. RUTF for HIV/AIDS patients should be administered considering the acceptability of the patient, allergies, and interaction with ARV.

5. Further detailed studies on the importance of RUTF and other nutritional aspects for HIV/AIDS are highly recommended.

\section{References}

1. Abd-AL-Salam, I., and Ahmed, L., (2009). Local Production of Ready To Use Therapeutic Food (RUTF) A dissertation submitted in partial fulfillment for the requirements of B.Sc. (Honor) in Health Science, AUW, Omdurman, Sudan.

2. Aungst BJ et al. Formulation and food effect on the oral absorption of a poorly water-soluble, highly permeable antiretroviral agent. Journal of PharmaceuticalScience, 2002, 91(6):13901395.

3. AwadElkariem, M. A., et al., (2002). A report in situation analysis, behavioral and epidemiology survey, Sudan National AIDS Control Program and Federal Ministry of Health.

4. Batterham MJ, Garsia R, Greenop P. Prevalence and predictors of HIV-associated weight loss in the era of highly active antiretroviral therapy. International Journal of STD \& AIDS, 2002, 13: 744-747.

5. Baum MK and Shor-Posner G. Micronutrient status in relationship to mortality in HIV-1 Disease. Nutr Reviews 1998; 51: S135-S139.

6. Baum MK, Shor-Posner G, Lu Y et al. Micronutrients and HIV disease progression. AIDS 1995; 9: 1051-1056.

7. Beach RS, Mantero-Atienza E, Shor-Posner G et al. Specific nutrient abnormalities in asymptomatic HIV-1 infection. AIDS 1992; 6: 701-708.

8. Briend A. (2001). Highly nutrient-dense spreads: a new approach to delivering multiple micronutrients to high-risk groups. Br J Nutr; 85 (suppl): S175-9.

9. Chen RY, Westfall AO, Mugavero MJ et al. Duration of highly active antiretroviral therapy. CID 2003; 37: 714-722.

10. Coors M (2001).. Acute phase response and energy balance in stable human immunodeficiency virus-infected patients: a doubly labeled water study. Journal of Laboratory and Clinical Medicine, 2001, 138:94-100.

11. Dannhauser A, van Staden AM, van der RE, (1999). Nutritional status of HIV1 seropositive patients in the Free State Province of South Africa: anthropometric and dietary profile. Eur J Clin Nutr;53:165-173.

12. Dibari F, Le Galle, I Ouattara A, Bahwere P, Seal A (2008). A qualitative investigation of Plumpy'nut consumption in adults enrolled in an MoH/MSF program in Kenya. Report on MSF Scientific Day.

13. Fawzi $W$ et al. Randomized trial of vitamin supplements in relation to transmission of HIV-1 through breastfeeding and early child mortality. AIDS, 2002, 16:1935-44.

14. Fawzi WW, Msamanga GI, Hunter D et al. Randomized trial of vitamin supplements in relation to transmission of HIV-1 through breastfeeding and early child mortality. AIDS 2002; 16(14): 1935-1944.

15. Fawzi WW. Micronutrients and HIV-1 Disease Progression among Adults and Children. Clinical Infectious Diseases, 2003, 37 Suppl 2: S112-6.

16. Friis $\mathrm{H}$ et al. HIV and other predictors of serum folate, serum ferritin, and hemoglobin in pregnancy: a cross-sectional study in Zimbabwe. American Journal of Clinical Nutrition, 2001, 73:1066-73. 
17. Friis $\mathrm{H}$ et al. Iron, haptoglobin phenotype, and HIV-1 viral load: a cross-sectional study among pregnant Zimbabwean women. Journal of Acquired ImmuneDeficiency Syndromes, 2003, 33:74-81.

18. Gerald, J., (2002). AIDS Update, Stine Practice Hallinc Prentice Hall, Upper Saddle River, New Jersey, Pearson Education London.

19. Grinspoon S, Mulligan K. For the Department of Health and Human Services working group on the prevention and treatment of wasting and weight loss. HIV related to weight loss and wasting. In Supplement: Integrating nutritionmanagement into HIV medical management. Guest Editor, Celia Hayes. ClinicalInfectious Diseases, 2003, 36 (Suppl 2): S69-78.

20. Hadigan $C$ et al. Modifiable dietary habits and their relation to metabolic abnormalities in men and women with HIV-infection and fat redistribution.

21. Humphrey JH et al. Short-term effects of largedose vitamin A supplementation on viral load and immune response in HIV-infected women. Journal of acquired immune Deficiency Syndromes and Human Retrovirology, 1999, 20:44-51.

22. Jaimton S, Pepin J, Suttent $R$ et al. A randomized trial of the impact of multiple micronutrient supplementation on mortality among HIV-infected individuals living in Bangkok. AIDS 2003; 17: 2461-2469.

23. Kosmiski LA (2003). Total energy expenditure and carbohydrate oxidation are increased in the human immunodeficiency virus lipodystrophy syndrome. Metabolism, 2003, 52:620-625.

24. Kumwenda $\mathrm{N}$ et al. Antenatal vitamin $\mathrm{A}$ supplementation increases birth weight and decreases anemia among infants born to human immunodeficiency virus-infected women in Malawi. Clinical Infectious Diseases, 2002, 35:618-24. Epub 2002 Aug 02.

25. Macallan DC (1995). Whole-body protein turnover from leucine kinetics and the response to nutrition in human immunodeficiency virus infection. American journal of Clinical Nutrition, 1995, 61:818826.

26. Manary MJ, Ndkeha MJ, Ashorn P, Maleta K, Briend A. (2004). Home-based therapy with RUTF for severe malnutrition with a ready-touse food. Arch Dis Child 2004;89:557- 61.
27. Michael A, Heidi S, MacDonald J, Per Ashorn, A., Heather M., and Mark J., (2005) Comparison of home-based therapy with ready-to-use therapeutic food with standard therapy in the treatment of malnourished Malawian children: a controlled, clinical effectiveness trial1-4, $\mathrm{Am}$ J ClinNutr81:864 -70.

28. MILDMAY (2005). International In association with the Regional AIDS Training Network Rehabilitation and Palliative Care for People Living with HI V/AIDS. The Mildmay International Study Centre The Mildmay Centre Plot127, Entebbe Road, Naziba Hill, Lubowa, LwezaP.O. Box 24985, Kampala Uganda E-mail: miscmildmay.or.ug.

29. Mocchegiani E, Muzzioli M. Therapeutic application of zinc in human immunodeficiency virus against opportunistic infections. J Nutr2000; 130 (5S): 1424S-1431S.

30. Muller F, Svardal AM, Norday I et al. Virological and immunological effects of antioxidant treatment in patients with HIV infection. Euro J Clin Invest 2000; 30 (10): 905914.

31. Polsky B, Kotler D, Steinhart C. HIV-associated wasting in the HAART era: guidelines for assessment, diagnosis, and treatment. AIDS Patient Care STDs, 2001, 15:411-423.

32. Rousseau MC, Molines C, Moreau J, Delmont J. Influence of highly active antiretroviral therapy on micronutrient profiles of HIVinfected patients. Ann NutrMetab2000; 44 (56): 212-216.

33. Sandige H, Ndekha MJ, Briend A, Ashorn P, Manary MJ. (2004) Locally produced and imported ready-to-use-food in the homebased treatment of malnourished Malawian children. J Pediatr Gastroenterol Nutr;39: 1416.

34. Shabert JK, Winslow C Lacey JM et al. Glutamine-antioxidant supplementation increases body cell mass in AIDS patients with weight loss: A randomized, double-blind controlled trial. Nutrition 1999; 15: 860-864.

35. Shevitz AH, Knox TA. Nutrition in the era of highly active antiretroviral therapy. CID 2001; 32: 1769-1775.

36. Sorensen JM. Herb-drug, food-drug, nutrientdrug and drug-drug interactions: mechanisms involved and their medical implications. Journal of Alternative and Complementary Medicine, 2002, 8: 293-308. 
37. Suttmann U, Ockenga J, Selberg 0 et al. Incidence and prognostic value of malnutrition and wasting in human immunodeficiency virus-infected outpatients. J Acquir Immun DeficSyn1995; 8: 239-246.

38. UNAIDS, (2005) Young People and HIV/AIDS Opportunity in Crisis, United Nations Programme on HIV/AIDS and World Health Organization.

39. Villamor E et al. Effect of multivitamin and vitamin A supplements on weight gain during pregnancy among HIV-1 infected women. American Journal of Clinical Nutrition, 2002, 76:1082-90.

40. Wanke CA, Silva M, Knox TA et al. Weight loss and wasting remain common complications in individuals infected with human immunodeficiency virus in the era of highly active antiretroviral therapy. CID 2000; 31: 803-805.

41. Wheeler DA, Gilbert CL, Launer CA et al. Weight loss as a predictor of survival and disease progression in HIV infection. $J$ Acquir Immune DeficSyn1998; 18: 80-85.
42. WHO (2004). Participant Handbook, Comprehensive HIV/AIDS Counselor Training. Organized by WHO in Partnership with SNAP and PPFA for Civil Society Organizations.

43. WHO (2005a). AIDS in Africa, the challenges and solutions. www.who.org/organizatoin. accessed $1^{\text {st }}$ July 2009.

44. WHO (2005b). Summary Country Profile For HIV/AIDS Treatment Scale-Up, World Health Organization, WHO, Sudan Country Report.

45. WHO, (2003b). Nutrient requirements for people living with HIV/AIDS, Report of technical consultation, World Health Organization, Geneva.

46. WHO, (2005c). World Health Organization. Conference on Nutrition and HIV/AIDS in Africa: Evidence, lessons, and recommendations for action. Executive summary of a scientific review. Geneva: WHO.

47. WHO. (2003a). Nutrient requirements for people living with HIV/AIDS. Report of a technical consultation. World Health Organization, Geneva, 2003. 